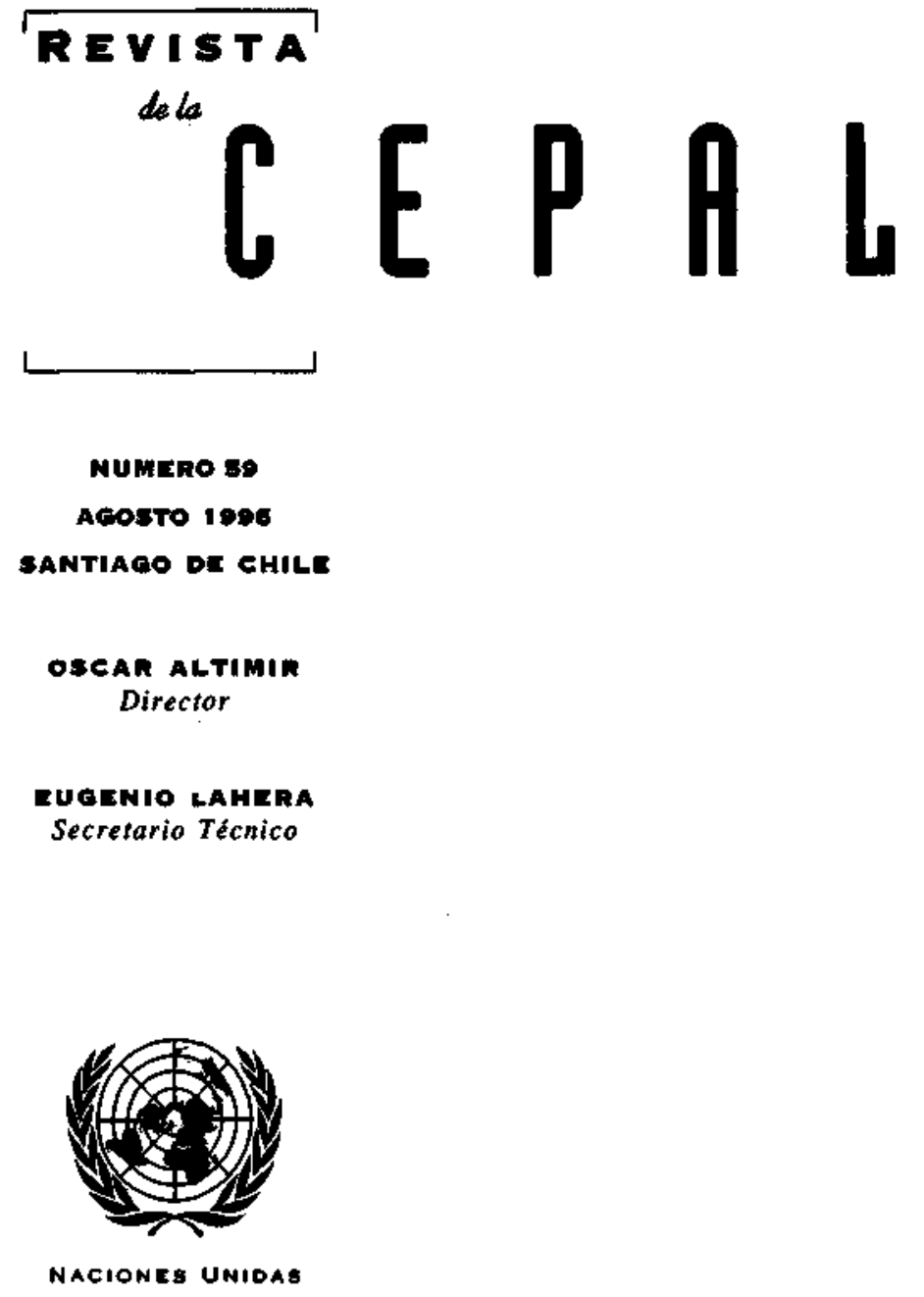


Interacciones entre macro y microeconomía

Gert Rosenthat

Politica económica, instituciones y desarrollo productivo en América Latina

Osvaldo Rosales

Competitividad sistémica: nuevo desafío para las empresas y la política

Klaus Esser, Wolfgang Hillebrand, Dirk Messner y Jörg Meyer-Stamer

La formación de habilidades báslcas y la capacitación para el trabajo productivo

Guillermo Labarca

Los fondos de inversión social en América Latina

Gabriel Siri

Mercados de derechos de agua: componentes institucionales

Miguel Solanes

Los países del Caribe y el área de libre comercio de las Amérlcas

Trevor Harker, Sidya Ould El-Hadj y Lucio Vinhas De Souza

La experiencia argentina: ¿desarrollo o sucesión de burbujas?

Hugo Nochteff

Posibilidades y límites de la reforma en la gestión de

la salud en Chile

Ana Sojo

Orientaciones para los colaboradores de la Revista de la CEPAL 


\section{Política económica, instituciones y desarrollo productivo en América Latina}

\section{Osvaldo Rosales V.}

Oficial de Asuntos Económicos Secretaria Ejecutiva, CEpAL
La CEPAL ha presentado a los gobiernos de la region un balance de las reformas económicas acaecidas en los últimos quince años y, derivado de él, una propuesta para fortalecer el proceso de desarrollo. De tal balance surge como mensaje central la necesidad de avanzar hacia una mayor articulación entre macroeconomía, microeconomía e institucionalidad, reforzando la complementariedad entre las fuentes macroeconómicas y microeconómicas de la competitividad y fortaleciendo la institucionalidad del desarrollo productivo. Sin afectar a las fuentes macroeconomicas de la competitividad -inflación baja y declinante, estímulos al ahorro e inversión y un tipo de cambio competitivo-, cabe diseñar las políticas microeconomicas que abran espacio a las nuevas fuentes de ella: capacitación y productividad, innovación y difusión tecnológica, infraestructura e inversión en el exterior. De lo que se trata es de un enfoque unificado que, preservando una estabilidad macroeconomica funcional al crecimiento y apoyado en mayores esfuerzos de ahorro e inversión, se aboque a una difusión más acentuada del progreso técnico, con incrementos de productividad menos heterogéneos que los actuales. Ello parecería exigir un mayor equilibrio institucional y de recursos entre las políticas macroeconómicas y las de desarrollo productivo, perfeccionando en estas últimas la evaluación y pertinencia de los instrumentos, su desempeño y la descentralización en la gestión, y reforzando sus vínculos con el crecimiento y la eficiencia. 
I

\section{Transformaciones económicas:}

\section{visión de conjunto}

Los años ochenta constituyen una línea divisoria en el comportamiento de las economías de América Latina y el Caribe. Todos los países, con secuencias, intensidades y resultados diferenciados, experimentaron fundamentales transformaciones tanto en el contenido de las políticas y estrategias económicas como en los propios sistemas productivos y en su relación con la economía mundial.

Tales reformas, detonadas por la crisis de la deuda externa, surgen del monumental esfuerzo desplegado por todos los países, cada uno según sus posibilidades y características, por adaptar sus economías a las nuevas circunstancias internas (gradual agotamiento de una modalidad de desarrollo) y externas (cambio tecnológico y globalización económica).

Distando mucho de ser similares, todos los procesos de reforma han perseguido metas de estabilización macroeconómica y competitividad internacional, sobre la base de la disciplina fiscal, la liberalización comercial y financiera, un mayor énfasis en los mecanismos de mercado, mayor confianza en la inversión privada y nuevos regímenes de incentivos y marcos regulatorios. Los rasgos diferenciadores de la estrategia económica se aprecian en la intensidad de las reformas, en la secuencia entre éstas y las políticas de estabilización, en las modalidades de la política cambiaria (tipo de cambio fijo, reptante, con o sin banda de flotación) y de la liberalización de la cuenta de capital (grado de profundidad, secuencia entre apertura comercial y financiera), en la política antiinflacionaria (rapidez de la reducción inflacionaria, con o sin indización), en el grado de intervención correctora (transferencias y focalización del gasto público) y, por último y no menos importante, en el peso relativo del gasto

¿ El análisis de la cepal sobre los temas considerados en este artículo se expresa en un documento central, Fortalecer el desarrollo: Interacciones entre macro y microeconomía (CEPAL, 1996a) y en otro, de respaldo empírico, titulado América Latina y el Caribe: 15 años de desempeño económico (CEPAL, 1996b), a cuyas sendas lecturas se remite al lector tanto para el apoyo cuantitativo como para un examen más en profundidad de cada uno de estos temas. público en eI PIB y del gasto social en el gasto público.

En su conjunto, convergencias y especificidades configuran una transformación fundamental en el proceso de desarrollo regional. Las primeras permiten hablar efectivamente de un punto de inflexión en las estrategias; las segundas, invalidan resumir este proceso como el tránsito a un "modelo" homogéneo y de aplicación generalizada.

De hecho, un rasgo central que diferencia a las experiencias nacionales es el grado en que las reformas económicas han ido acompañadas de modificaciones institucionales. Ejemplos destacados son la autonomía de las autoridades monetarias, las reglas de comportamiento en la política fiscal y en la gestión de las empresas públicas, así como la supervisión y regulación prudencial del sistema financiero y el grado en que los procesos de privatización fueron acompa$\bar{n}$ ados de un fortalecimiento de los instrumentos e institucionalidad para la promoción de la competencia, incluyendo la regulación de los monopolios naturales.

En este mismo ámbito institucional, se aprecian tambiên diferencias significativas en las políticas de desarrollo productivo (con o sin instancias de concertación entre actores) y en los atributos específicos que en cuanto a grado y contenido tienen las políticas sectoriales.

Como consecuencia de tales procesos, los países de la región muestran logros en las esferas de la macroeconomía y la microeconomía. En la primera, con avances en estabilización de precios, y en menor medida, en crecimiento. A ello contribuyeron la disciplina fiscal y monetaria y, a partir de 1991, la copiosa afluencia de capitales externos, atribuible a las altas diferencias de rentabilidad pero también a la confianza inspirada por la gestión macroeconómica, las reformas estructurales y el avance hacia regímenes democráticos. Con todo, el crecimiento medio en la región en los años noventa fue moderado, respetable pero inferior al desempeño histórico y poco satisfactorio desde la doble óptica del progreso técnico y la superación de los rezagos sociales. 
La reestructuración productiva emergente no se ha traducido aún en suficiente generación de puestos de trabajo ni en adecuada disminución de las desigualdades, al grado que, en numerosos países, los indjcadores de equidad social no recuperan aún niveles previos a la crisis. Los empleos de buena calidad han aumentado en forma muy lenta, y las remuneraciones relativas de los trabajos de diferente calificación han tendido a distanciarse.

Las políticas de compensación social han tenido hasta ahora una eficacia limitada; el gasto social se ha visto constreñido por los esfuerzos de disciplina presupuestaria y la gestión de las políticas sociales no se ha renovado suficientemente.

Las economías continúan desenvolviéndose en un contexto de vulnerabilidad. En la mayoría de los cam sos, la estabilidad macroeconómica ha dependido de elevados déficit de balanza de pagos en cuenta corriente, financiados a veces con capitales volátiles, susceptibles de retirarse ante cualquier circunstancia que afecte la confianza de los inversores.

Uno de los rasgos sobresalientes de los años ochenta, en efecto, fue que, con diferencias de grado entre los distintos países, los coeficientes de ahorro, y en especial los coeficientes de inversión, cayeron bruscamente en relación a décadas anteriores. Si bien dichos coeficientes se han estado recuperando gradualmente en los años noventa, en la vasta mayoría de los países no han alcanzado aún los niveles previos a la crisis.

Los procesos de ajuste y reforma estructural actuaron como un poderoso mecanismo de selección que forzó a cada agente económico a adaptarse a los nuevos escenarios de señales de precios y de regulación de la actividad productiva.

Las actividades productivas más afectadas por el cambio en las reglas del juego y en los marcos regulatorios fueron las ramas industriales que producían para el mercado interno, que hacían uso relativamente intensivo de ingeniería local; las firmas pequeñas y medianas, y el conjunto de las empresas estatales. Por el contrario, los sectores que participaban de la exportación, las actividades vinculadas a los recursos naturales, los grandes conglomerados de capital nacional y muchas empresas transnacionales pudieron adaptarse con más éxito a las nuevas circunstancias.

Se comprueba una reorientación productiva hacia bienes transables que hacen uso intensivo en recursos naturales, sobre todo la minería, mientras que en bienes no transables, la energía, la construcción y el transporte crecen más que el PIB. En el Caribe des- taca el peso del turismo, la maquila y los servicios asociados a la transmisión de datos. El sector industrial se reestructura desde un patrón de especialización basado en el complejo metalmecánico a otro apoyado en una alta densidad de recursos naturales (aluminio, productos petroquímicos, celulosa y papel, alimentos y metales no ferrosos). Como contrapartida hay un retroceso en productos textiles, cuero y calzado, bienes de capital y química fina.

Se aprecian auspiciosos procesos de incorporación tecnológica en la explotación y gestión productiva de los recursos naturales (agricultura, silvicultura, pesca y minería) y asimismo procesos de modernización en los servicios financieros, telecomunicaciones, energía y transporte.

Sin embargo, la heterogeneidad estructural característica de los aparatos productivos de la región se ha acentuado, en la medida en que han tendido a ampliarse las diferencias de productividad entre las empresas grandes que lideran el proceso de modernización y el amplio y variado universo de las actividades rezagadas en el mismo proceso. ${ }^{l}$ Esto no sólo sienta las bases de mayores desigualdades sociales, al acentuar las disparidades internas de productividad y los grados de concentración económica en la estructura productiva. También afecta la capacidad de crecimiento, al limitar la difusión de enlaces, y de progreso técnico y la capacidad de arrastre de las exportaciones.

Las economías de la región muestran una notable reorientación hacia el exterior, fuertemente apoyada en una explotación más intensa de los recursos naturales. El coeficiente de exportaciones se elevo de $14 \%$ del PIB en 1980, a $21 \%$ en 1990 y a $25 \%$ en 1995.

Se percibe un dinamismo importante al que contribuyen los acuerdos comerciales y la profundización de los esquemas de integración, con notables incrementos del comercio e inversiones intrarregionales, con aumentos de competitividad en número creciente de empresas y sectores productivos y con notorios avances en la capacidad empresarial para conquistar mercados externos. Se aprecian también avances en la diversificación exportadora y en la aplicación del progreso técnico (explotación de recursos naturales, cadena de distribución agrícola y ramas industriales con alto uso de recursos naturales).

Si bien, como tendencia general, la participación

\footnotetext{
${ }^{1}$ Los incrementos de productividad se localizan en el sector indus. trial moderno, agricultura de exportación, grandes empresas mineras, energía, telecomunicaciones y servicios financieros. Tíenden a concentrarse bastante entre sectores y al interior de ellos.
} 
de los productos primarios en el total exportado se reduce, el mayor peso relativo de las manufacturas y semimanufacturas refleja un fuerte sesgo hacia actividades industriales que procesan recursos naturales. El peso relativo de las ventas externas de productos básicos --alimentos, productos agrícolas no alimenticios, metales y minerales, combustibles- continúa siendo superior al promedio de los países en desarrollo. A la vez, se mantiene un superávit comercial en productos primarios que contribuye a financiar el déficit neto en los sectores industrial y de servicios.

Por lo anterior, parte del esfuerzo exportador se ve neutralizado por una estructura exportadora aún muy concentrada en productos de bajo dinamismo y precios con tendencia declinante y erráticos en el corto plazo.

\section{II}

\section{Institucionalidad y transformación productiva}

La excesiva confianza en la efectividad "automática" de las señales macroeconomicas y en las reformas ha llevado a subestimar la debilidad de las instituciones $\mathrm{y}$ las fallas de los mercados (que pueden ser imperfectos, segmentados o incompletos, o bien estar distorsionados por externalidades), y acaso a depender en exceso de la capacidad de la política macroeconómica para desencadenar por sí sola la dinámica del crecimiento y la incorporación del progreso técnico. Al tender a integrarse los esfuerzos de estabilización con los de ajuste estructural, se han reconocido las raíces estructurales de la inestabilidad macroeconómica.

Dicho reconocimiento debiera conducir a abordar las preocupaciones sobre el funcionamiento actual y las potencialidades de crecimiento de las economías latinoamericanas y caribeñas desde una optica que integre los escenarios macroeconómicos, las instituciones y los marcos regulatorios, el funcionamiento de los mercados de factores y el comportamiento microeconómico. Al considerar tales interacciones, se entienden mejor las dificultades prácticas para alcanzar, simultáneamente, estabilidad macroeconómica, vigoroso crecimiento, niveles satisfactorios de empleo, y tasas de ahorro, de inversión y de progreso técnico suficientes para asegurar un desarrollo sostenido.

En casi todas las economías de la region, en mayor o menor medida, hay problemas estructurales e institucionales que hacen diff́cil lograr un incremento sostenido del crecimiento sólo sobre la base de las señales de mercado. Por una parte, las actuales actividades basadas en recursos naturales o el suministro de servicios públicos presentan más ventajas de corto plazo en términos de riesgo y de rentabilidad que muchas actividades promisorias que requieren el desarrollo de capacidades tecnológicas; por otra, los vacíos del mercado de capitales limitan las inversiones rentables a más largo plazo y el despliegue de innovaciones en la producción.

La existencia de mercados segmentados o incompletos disminuye las posibilidades de multiplicar los eslabonamientos al interior de los sistemas productivos y también la irradiación de demanda y progreso técnico desde los sectores líderes hacia el resto de la economía. Por otro lado, los mercados financieros segmentados o incompletos tampoco garantizan la adecuada canalización de ahorro hacia la inversión. ${ }^{2}$

Las deficiencias estructurales de los mercados financieros de la región afectan la inversión y la innovación. La segmentación del crédito sigue excluyendo en buena medida a las empresas pequeñas y medianas del acceso a las corrientes principales de fondos. Elevados márgenes de intermediación bancaria transforman bajas tasas de interés pasivas reales en tasas activas reales que son gravosas para las actividades productivas. En general, los sistemas financieros continúan funcionando según una lógica que privilegia más las garantías que la rentabilidad de los proyectos.

En lo que se refiere a las políticas de desarrollo productivo, lo que se persigue es incrementar la productividad total de los factores, mejorar la calidad de bienes y servicios y promover la generación y difusión tecnológica a través de un conjunto de acciones centradas en el desarrollo y fortalecimiento de los sis-

\footnotetext{
2 En ese tipo de mercados, a inicios de los años noventa, la inyeccín de cuantiosos recursos externos produjo auges importantes de actividad financiera y bursátil, canalizados en abundante medida hacia el consumo y las inversiones en actividades no transables, mediante colocaciones que en su mayoria fueron de corto plazo.
} 
temas innovativos nacionales. Estos últimos deben propiciar una efectiva interacción entre los diversos actores institucionales involucrados, y deben basarse crecientemente en recursos destinados a la innovación por el sector privado. Las medidas para reforzar tales sistemas comprenden, entre otras, el apoyo a redes de información, el fortalecimiento de la base empresarial, la protección a la propiedad intelectual, la promoción de centros de investigación y extensión de tecnología sectorial, la adopción de normas y estándares internacionales de calidad y la capacitación y formación profesional.

La institucionalidad pública dedicada al diseño y ejecución de políticas de desarrollo debe adaptarse al ritmo del proceso de internacionalización de las eco- nomías de la región. En particular, corresponde readecuar las políticas e instrumentos a los compromisos derivados de acuerdos multilaterales o del avance en los esquemas de integración. En igual sentido, el fomento exportador exige hacer mayor hincapié en los temas de la inversión en el exterior y la participación en cadenas de comercialización, así como en la calidad y diferenciación de marca.

El mensaje central es el de avanzar hacia una mayor articulación entre macroeconomía, microeconomía e institucionalidad, reforzando la complementariedad entre las fuentes macroeconómicas y microeconómicas de la competitividad y el fortalecimiento de la institucionalidad del desarrollo productivo.

\section{III}

\section{El balance de la política económica}

\section{Ajuste y brecha externa}

En la evolución de la brecha externa desde la crisis de la deuda al presente se observan dos períodos claramente diferenciados, en función del signo de la transferencia neta de recursos y de la influencia que ejerció en el desempeño económico. El primero, 1982 a 1990 , es un período de ajuste y transferencia neta negativa de recursos equivalente a un $3.2 \%$ del PIB; el segundo, 1991 a 1994, es una etapa de recuperación apoyada en el ahorro externo, en la que los países recibieron una transferencia positiva equivalente al $1.5 \%$ del PIB.

El período 1982-1990 mostró un desempeño económico alejado de la frontera productiva, con un producto efectivo bastante inferior al potencial, lo que redund 6 en marcada subutilizacion de los recursos productivos y -en conjunto con la inestabilidad-en una acentuada baja de la inversión, que a su vez limitó la expansión futura del producto. Todo ello se tradujo en lento crecimiento, reducción del PIB por habitante y en una demanda interna virtualmente estancada hasta 1990.

En ese período, debido a la restricción de los créditos internacionales, el equilibrio de la cuenta corriente adquirio una importancia prioritaria. Ante la necesidad de destinar grandes sumas al pago de intereses y a la remesa de utilidades, que provocaba un déficit en la cuenta de servicios financieros, los países se vieron en la obligación de lograr un superávit comercial significativo, lo que a su vez exigía tipos de cambio real elevados y superiores a los de largo plazo. En los años noventa, una vez reducida la brecha externa, ese objetivo se sustituyó por el financiamiento de la balanza de pagos, para lo cual era preciso captar capitales que permitieran financiar un déficit creciente en cuenta corriente. Salvo algunas excepciones, el tipo de cambio real dejo de ser un instrumento relevante de la política económica y pasó a estar determinado por la cuantía de las corrientes de capital.

Ya a comienzos de la actual década se revirtió la transferencia negativa de recursos financieros prevaleciente entre 1982 y 1990 . Los países de la región recuperaron el acceso al financiamiento externo privado, que alcanzó una gran magnitud y provino de variadas fuentes, si bien éstas mostraron más preferencia por el corto plazo que en otras zonas en desarro110.3

\footnotetext{
${ }^{3}$ Entre 1990 y 1994 los flujos de cartera de todos los países en desarrollo representaron el $41 \%$ de la afluencia de recursos externos, con un $37 \%$ correspondiente a inversión extranjera directa (IED), mientras que en la región los primeros ascendieron a $66 \%$ y los de IED a 30\%. En cambio, en Asia se observo una marcada preferencia por el largo plazo (45\% en IED), en tanto que sólo el $24 \%$ de los recursos correspondió a flujos de cartera (FMI, 1995).
} 
La inversión extranjera directa y la inversión de cartera aumentaron en respuesta a la colocación de bonos y acciones, ya sea directamente o mediante ADR y GDR, en tanto que el financiamiento oficial y la deuda privada se redujeron. Los flujos netos de capital expresados como proporción del PIB alcanzaron a un $5 \%$ en 1992-1994, nivel superior al máximo histórico anterior (4.5\% en 1977-1981). Aunque la afluencia de recursos se concentró en México, Argentina, Brasil, Chile y Perú, en 11 países de la región la entrada de capital ascendió a más del 5\% del producto.

Al atenuarse la restricción externa, entre 1992 y 1994 se produjo una voluminosa entrada neta de recursos que permitió cubrir el creciente déficit comercial y en la cuenta corriente. En efecto, a partir de 1992 el déficit comercial reapareció, el incremento de las importaciones duplicó al de las exportaciones y el déficit en cuenta corriente superó el 5\% del PIB en nueve países (Bolivia, Costa Rica, Guatemala, Haití, Honduras, México, Nicaragua, Paraguay y Perú), aunque en la mayoría el ingreso en la cuenta de capital compensó con creces ese desequilibrio.

Entre 1991 y 1994, la entrada de capitales puso fin a la restricción externa, ayudando a reactivar la producción y la demanda interna, con efectos favorables en el empleo y los salarios. Las inversiones aumentaron, impulsadas por el cambio de clima macroeconómico y apoyadas en la afluencia de capitales que contribuyeron a financiar el déficit creciente de la cuenta corriente hasta 1994. Por otra parte, la tasa de inflación se redujo considerablemente y el sector público registró un superávit o bien un déficit reducido y manejable. En este contexto, las economías recuperaron en cierta medida la capacidad de crecimiento, en un marco de mayor estabilidad y atenuación de la restricción externa.

\section{Estabilización aún no consolidada}

Al comparar el ambiente macroeconómico de mediados de los años noventa con el del segundo quinquenio de la década anterior, se observan cambios importantes: moderada expansión del nivel de actividad, menor tendencia al déficit en el sector público, crecimiento más limitado de la oferta monetaria, recuperación de las tasas de inversión y baja del desempleo.

Un ambiente financiero internacional más propicio a combinaciones adecuadas de políticas de ajuste y de financiamiento, permitió que las reformas y la mejor calidad de las políticas económicas se reflejasen en una tendencia decreciente del ritmo inflaciona- rio en la mayor parte de los casos, destacando al respecto las experiencias de Bolivia, desde mediados de los ochenta, y de Argentina, Brasil, Nicaragua y Perú, más recientemente. En la presente década, aumentó el número de países con inflación inferior o cercana al $10 \%$, lo que contrasta en forma marcada con lo ocurrido en los años anteriores (cuadro 1).

El mayor financiamiento externo, al permitir la apreciación real de la moneda, ha contribuido a la estabilización en varios países. El empleo de "anclas nominales" es importante en todo proceso de estabilización, sobre todo cuando éste se inicia después de episodios de hiperinflación y fuga de capitales; si bien su aporte se potencia cuando forma parte de un conjunto de medidas de saneamiento duradero de la situación fiscal y de refuerzo de la solvencia del sistema financiero.

Una de las lecciones importantes de la crisis de la deuda fue reconocer que el aumento súbito de la disponibilidad de recursos externos suele traducirse en un incremento insostenible del consumo. Para evitarlo es preciso destinar la mayor parte de los recursos financieros disponibles a inversión real, con el fin de ampliar la futura capacidad de pago de las economías; de lo contrario, la estabilización será transitoria. ${ }^{4}$

Para alcanzar y mantener un ritmo inflacionario bajo y sostenible a largo plazo, en un contexto de apertura comercial y financiera, se requiere un nivel adecuado de desarrollo, diversificación y flexibilidad de los sectores exportadores y productores de bienes transables. La estabilidad de los estímulos a este sector es un requisito importante para consolidar la estabilización, de modo que la experiencia aconseja evitar revaluaciones reales pronunciadas, ojalá acotándolas a ritmos compatibles con el incremento de productividad en el sector de bienes transables.

\section{Ajuste fiscal precario}

La crisis de las finanzas públicas en la gran mayoría de los países de la región fue uno de los aspectos más importantes de las conmociones económicas que sufrió la región en el decenio de 1980 (CEPAL, 1993). En la presente década se ha producido una situación dia-

\footnotetext{
${ }^{4}$ Un factor decisivo en el éxito de las políticas de estabilización es la consecución de niveles elevados y estables de inversion. La inflación afecta adversamente la inversión y su eficiencia, limitando el potencial de crecimiento. De allí que una estabilización exitosa deba irse reflejando en mayores tasas de crecimiento y elevados niveles de inverșión.
} 
CUADRO I

América Latina y el Caribe: tendencias de algunas variables macroeconómicas, 1986-1990 y 1991-1994 (Número de palses)

\begin{tabular}{|c|c|c|c|c|c|c|c|}
\hline Tendencia & $\begin{array}{l}\text { Déficit } \\
\text { del sector } \\
\text { público }\end{array}$ & $\begin{array}{l}\text { Superávit } \\
\text { del sector } \\
\text { público }\end{array}$ & $\begin{array}{l}\text { Crecimiento } \\
\text { monetario } \\
\text { (M1) }\end{array}$ & $\begin{array}{l}\text { Inversión } \\
\text { bruta } \\
\text { fija/PIB }\end{array}$ & $\begin{array}{l}\text { Tipo de cambio } \\
\text { real de las } \\
\text { exportaciones }\end{array}$ & $\begin{array}{l}\text { Remunera- } \\
\text { ciones reales } \\
\text { medias }\end{array}$ & $\begin{array}{c}\text { Desempleo } \\
\text { urbano }\end{array}$ \\
\hline $\begin{array}{l}\text { Creciente } \\
1986-1990 \\
1991-1994\end{array}$ & $\overline{4}$ & $\begin{array}{l}1 \\
2\end{array}$ & $\begin{array}{l}8 \\
4\end{array}$ & $\begin{array}{l}5 \\
8\end{array}$ & $\begin{array}{l}7 \\
4\end{array}$ & $\begin{array}{l}3 \\
11\end{array}$ & $\begin{array}{l}7 \\
3\end{array}$ \\
\hline $\begin{array}{l}\text { Decreciente } \\
1986-1990 \\
1991.1994\end{array}$ & $\begin{array}{l}6 \\
4\end{array}$ & $\overline{1}$ & $\begin{array}{c}6 \\
10\end{array}$ & $\begin{array}{l}7 \\
1\end{array}$ & $\begin{array}{l}4 \\
5\end{array}$ & $\begin{array}{l}7 \\
1\end{array}$ & $\begin{array}{l}5 \\
3\end{array}$ \\
\hline $\begin{array}{l}\text { Estable } \\
1986-1990 \\
1991-1994\end{array}$ & $\overline{3}$ & $\bar{i}$ & $\overline{1}$ & $\begin{array}{l}1 \\
8\end{array}$ & 6 & $\begin{array}{l}3 \\
3\end{array}$ & $\begin{array}{l}\text { I } \\
9\end{array}$ \\
\hline $\begin{array}{l}\text { Variable } \\
1986-1990 \\
1991-1994\end{array}$ & $\begin{array}{l}11 \\
3\end{array}$ & - & $\begin{array}{l}3 \\
1\end{array}$ & $\begin{array}{l}5 \\
i\end{array}$ & $\begin{array}{l}6 \\
2\end{array}$ & $\begin{array}{l}2 \\
-\end{array}$ & $\begin{array}{l}4 \\
3\end{array}$ \\
\hline
\end{tabular}

Fuente: CEPAL, sobre la base de datos oficiales.

metralmente opuesta, por lo menos hasta 1994, ya que casi todas las economías han gozado de una relativa estabilidad, gracias a los adelantos logrados a partir de 1991, sobre todo en virtud de los procesos de ajuste fiscal iniciados en los años anteriores y la reanudación del financiamiento externo. Aunque la evolución de los países es diś́mil, en los años noventa se observa una tendencia generalizada a la reducción del desequilibrio fiscal.

Los procesos de ajuste fiscal de gran magnitud se iniciaron en la primera mitad del decenio de 1980 , el período en que fue más intensa la crisis de la deuda externa, y permitieron una reducción del déficit fiscal de cinco a seis puntos del producto en la mayoría de los países de la región. Salvo contadas excepciones, estos procesos no dieron resultados satisfactorios, debido a que las condiciones externas seguían siendo adversas.

La reanudación del crédito externo y del crecimiento y la estabilidad de precios, que caracterizaron la economía latinoamericana en el período 1990-1994, contribuyeron al mejor desempeño fiscal. La posibilidad de financiamiento voluntario en los mercados internacionales aumentó los márgenes del endeudamiento interno y redujo sus costos. La apreciación cambiaria, vinculada también al ingreso de capitales y a la acumulación de reservas, disminuyó la carga real del pago de intereses de la deuda externa en los presupuestos públicos. Los ingresos tributarios respondieron elásti- camente a la aceleración de la actividad y la baja de la inflación mejoró la recaudación real (cuadro 2).

Todos estos factores, junto a las reformas estructurales, contribuyeron a configurar una nueva situación en el ámbito fiscal. Por sus efectos en las finanzas públicas destacan las modificaciones tributarias, como el mayor énfasis en los impuestos al consumo, la ampliación de la base imponible y reducción de las alícuotas, la disminución de los aranceles aduaneros y los avances en fiscalización tributaria. Han influido decisivamente en algunas experiencias la venta de empresas públicas y la extensión de las privatizaciones de servicios públicos. Además, se profundizó la descentralización, se redimensionó la propia administración pública y se aceleraron los procesos de privatización de los sistemas de seguro social (médico y previsional).

Las secuelas de la crisis de la deuda aún pesan sobre la política fiscal, considerando incluso que la propagación de crisis financieras localizadas se ha traducido en varios casos nacionales en operaciones de rescate de elevado costo fiscal. Por otra parte, la modalidad de ajuste fiscal, a veces excesivamente apoyada en la contracción de gastos, ha limitado severamente la inversión social y en infraestructura, junto con mermar considerablemente las remuneraciones del sector público y la propia calidad de su desempeño.

La situación fiscal a veces puede verse distorsionada cuando ingresos excepcionales por privatiza- 


\begin{tabular}{|c|c|c|c|c|c|c|c|c|c|c|c|c|c|c|c|c|}
\hline Paises & Nivel ${ }^{\mathbf{b}}$ & 1980 & 1981 & 1982 & 1983 & 1984 & 1985 & 1986 & 1987 & 1988 & 1989 & 1990 & 1991 & 1992 & 1993 & 1994 \\
\hline Argentina & $\begin{array}{c}\text { SPNFN } \\
\text { SP }\end{array}$ & $-5.5^{b}$ & -9.6 & -10.6 & -10.5 & -8.3 & -4.3 & -3.3 & -5.3 & -8.2 & -3.7 & -3.8 & -1.6 & $\begin{array}{l}-0.1 \\
-0.9\end{array}$ & $\begin{array}{l}-0.1 \\
-0.3\end{array}$ & $\begin{array}{l}-0.4 \\
-0.7\end{array}$ \\
\hline Bolivia & SPNF & -7.8 & -7.6 & -14.2 & -17.9 & -26.6 & -10.9 & -3.1 & -7.3 & -5.8 & -4.8 & -3.9 & -3.7 & -4.8 & -5.8 & -4.2 \\
\hline Brasil & SPC & -1.6 & -3.2 & -4.1 & -4.1 & -3.4 & -4.2 & -3.6 & -5.7 & -4.8 & -6.9 & 1.2 & -0.2 & -2.8 & -1.3 & 1.2 \\
\hline Chile & GC & 6.5 & 2.8 & -3.4 & -2.6 & -2.9 & -3.8 & -0.8 & 1.9 & 1.7 & 2.8 & 3.5 & 2.4 & 2.8 & 2.0 & 2.0 \\
\hline Colombia & SPNF & -2.6 & -5.3 & -6.0 & -7.6 & -6.3 & -4.0 & -0.3 & -1.9 & -2.2 & -1.9 & -0.6 & - & -0.2 & 0.3 & 2.6 \\
\hline Costa Rica & $\begin{array}{c}G C \\
\text { SPNF }\end{array}$ & -8.1 & -3.5 & -2.6 & -4.3 & -3.1 & $\begin{array}{l}-2.0 \\
-1.7\end{array}$ & $\begin{array}{l}-3.4 \\
-1.8\end{array}$ & $\begin{array}{r}-2.0 \\
-\end{array}$ & $\begin{array}{l}-2.5 \\
0.1\end{array}$ & -4.1 & $\begin{array}{l}-4.4 \\
-2.5\end{array}$ & $\begin{array}{l}-3.1 \\
-0.1\end{array}$ & $\begin{array}{r}-1.9 \\
0.7\end{array}$ & $\begin{array}{r}-1.9 \\
0.6\end{array}$ & $\begin{array}{l}-7.0 \\
-6.9\end{array}$ \\
\hline Ecuador & SPNF & -7.4 & -8.5 & -7.2 & -5.2 & -1.2 & 0.2 & -3.7 & -9.6 & -5.3 & -1.6 & 0.6 & -1.0 & -1.7 & -0.4 & -0.2 \\
\hline El Salvador & GC & -5.3 & -6.6 & -7.0 & -8.8 & -5.8 & -3.8 & -2.8 & -3.8 & -3.2 & -4.9 & -3.6 & -5.2 & -5.2 & -3.3 & -2.1 \\
\hline Guatemala & GC & -4.7 & -7.4 & -4.7 & -3.3 & -3.8 & -1.8 & -1.9 & -2.4 & -2.4 & -3.8 & -2.3 & -0.1 & -0.5 & -1.5 & -1.5 \\
\hline Honduras & GC & -8.7 & -8.1 & -13.0 & -10.9 & -12.3 & -9.8 & -8.7 & -8.1 & -6.9 & -7.4 & -6.4 & -3.3 & -4.9 & -9.3 & -5.2 \\
\hline Nicaragua & $G C$ & -9.3 & -11.7 & -13.2 & -28.7 & -23.6 & -22.4 & -17.3 & -16.6 & -26.6 & -6.7 & -17.1 & -7.5 & -7.6 & -7.3 & -9.7 \\
\hline Panatná & GC & -9.3 & -7.8 & -12.9 & -5.7 & -6.7 & -2.1 & -1.9 & -4.5 & -5.3 & -7.0 & -0.7 & -2.7 & -1.4 & -0.4 & -0.8 \\
\hline Paraguay & GC & 0.3 & -2.2 & -0.1 & -2.0 & -2.5 & -1.2 & 1.0 & -0.2 & 0.7 & 1.5 & 3.0 & 4.4 & -0.1 & -0.7 & 0.8 \\
\hline Perú & GC & -2.4 & -4.0 & -3.2 & -7.5 & -4.4 & -2.2 & -3.7 & -5.7 & -2.5 & -4.2 & -2.5 & -1.4 & -1.4 & -1.6 & 2.1 \\
\hline $\begin{array}{l}\text { República } \\
\text { Dominicana }\end{array}$ & GC & -2.9 & -2.3 & -3.1 & -2.8 & -0.9 & +1.5 & -0.5 & -2.2 & -1.6 & -0.1 & 0.3 & 2.8 & 2.9 & -0.4 & -1.1 \\
\hline Unuguay & $\begin{array}{l}\text { GC } \\
\text { SPC }\end{array}$ & $1 \overline{1}$ & $\begin{array}{l}-1.5 \\
-1.8\end{array}$ & $\begin{array}{r}-9.1 \\
-11.1\end{array}$ & $\begin{array}{l}-3.9 \\
-4.0\end{array}$ & $\begin{array}{l}-5.2 \\
-4.5\end{array}$ & $\begin{array}{l}-2.9 \\
-2.3\end{array}$ & $\begin{array}{l}-1.2 \\
-0.7\end{array}$ & $\begin{array}{r}0.1 \\
-0.9\end{array}$ & $\begin{array}{l}-2.0 \\
-4.5\end{array}$ & $\begin{array}{l}-3.4 \\
-6.1\end{array}$ & $\begin{array}{l}-0.1 \\
-2.5\end{array}$ & $\begin{array}{r}0.4 \\
-\end{array}$ & $\begin{array}{l}0.3 \\
0.5\end{array}$ & $\begin{array}{l}-1.1 \\
-1.5\end{array}$ & $\begin{array}{l}-2.3 \\
-3.0\end{array}$ \\
\hline Venezuela & $\begin{array}{l}\text { GC } \\
\text { SPNF }\end{array}$ & -0.2 & 2.8 & -1.1 & $\begin{array}{l}-2.0 \\
-2.4\end{array}$ & $\begin{array}{l}2.5 \\
6.8\end{array}$ & $\begin{array}{l}2.3 \\
3.2\end{array}$ & $\begin{array}{l}-0.5 \\
-5.3\end{array}$ & $\begin{array}{l}-5.0 \\
-4.4\end{array}$ & $\begin{array}{l}-6.2 \\
-8.6\end{array}$ & $\begin{array}{l}-1.0 \\
-1.1\end{array}$ & $\begin{array}{r}-2.1 \\
0.2\end{array}$ & $\begin{array}{l}2.8 \\
0.2\end{array}$ & $\begin{array}{l}-3.6 \\
-5.8\end{array}$ & $\begin{array}{l}-3.4 \\
-3.5\end{array}$ & $\begin{array}{r}6.5 \\
-13.8\end{array}$ \\
\hline
\end{tabular}

Fuente: CEPAL, sobre la base de cifras oficiales.

a El signo (-) indica déficit

${ }^{b}$ En este cuadro se utilizan las siguientes abreviaturas: SPNFN = sector público no financiero nacional. SPNF = sector público no financiero. $S P=$ se refiere a la situación hipotética que se habría dado si no se hubieran computado los ingresos de privatización. SPC $=$ sector público consolidado. $\mathrm{GC}=$ gobierno central. 
ciones aparecen sobre la línea y no como mecanismos de financiación del déficit. ${ }^{5}$ Esto reduce artificialmente el déficit público y distorsiona el cambio en el patrimonio neto del sector público.

En tal sentido, no discriminar adecuadamente entre factores transitorios y permanentes puede afectar la estabilidad fiscal. En efecto, situaciones fiscales que aparecen equilibradas pueden deberse a ingresos externos transitoriamente altos que estimulan la actividad y la recaudación tributaria. Si tales ingresos no se ahorran y, peor aún, si se destinan a financiar gasto corriente, puede estarse incubando presiones de gasto excesivas que habrá que ajustar, una vez que los niveles de financiamiento externo retomen los patrones de tendencia.

\section{Insuficiencia del nivel de ahorro interno}

En los años ochenta, con diferencias de grado entre los distintos países, los coeficientes de ahorro, y en especial los coeficientes de inversion, cayeron bruscamente con respecto a décadas pretéritas. Si bien dichos coeficientes vienen recuperándose gradualmente en los años noventa, en la mayoría de los países no han alcanzado aún los niveles anteriores a la crisis.

Los estudios al respecto, ${ }^{6}$ destacan que las tasas de interés, si bien contribuyen a la utilización más eficiente de los recursos disponibles y a regular los movimientos de capitales, no inciden decisivamente en la determinación de los volúmenes de ahorro; que se requieren políticas que refuercen la complementariedad tanto entre ahorro externo y nacional como entre ahorro público y privado.

$\mathrm{El}$ ahorro presenta en la región tres características fundamentales: i) estabilización en torno a una tasa equivalente a $20 \%$ del PIB; ii) tendencia al desplazamiento del ahorro nacional por el incremento del ahorro externo; iii) desplazamiento parcial del ahorro privado por ahorro público.

Vale decir, en la región se han producido conflictos entre las distintas fuentes de ahorro. El incremento del ahorro público ha compensado en gran medida

\footnotetext{
5 En términos macroeconómicos, financiar el déficit con ingresos por privatizaciones es equivalente a hacerlo con endendamiento páblico, a través de la emisión de bonos. En efecto, la venta de activos públicos altera la posición patrimonial del fisco, por un lado, y por otro, absorbe fondos de ahorro privado, con un efecto sobre el mercado financiero similar a la emisión de deuda pública (Marcel, 1989).

${ }^{6}$ Entre ellos, dos reseñas realizadas por la CEPal: Massad y Eyzaguirre (1990), y Held y Uthoff (1995).
}

la declinación del privado. A la vez, el aumento del ingreso disponible real, derivado del influjo de un mayor volumen de ahorro externo, se ha canalizado en forma desproporcionada al consumo y ha desplazado el ahorro nacional en todas sus formas (gráficos 1 y 2).

El ahorro nacional bruto como proporción del PIB (a precios corrientes) se mantuvo relativamente estable en el período 1974-1981, durante el cual la elevada liquidez internacional dio acceso a los países al financiamiento externo, específicamente a préstamos bancarios. Disminuyó luego con la crisis de la deuda y el ajuste de la actividad económica ante la interrupción del financiamiento externo. Y volvió a aumentar posteriormente, ante la recuperación del nivel de ingreso disponible per cápita, aunque la tendencia al alza

GRÁFICO

América Latina y el Caribe: Indicadores de ahorro nactonal y ahorro externo a precios corrientes $(\%$ del PIB)

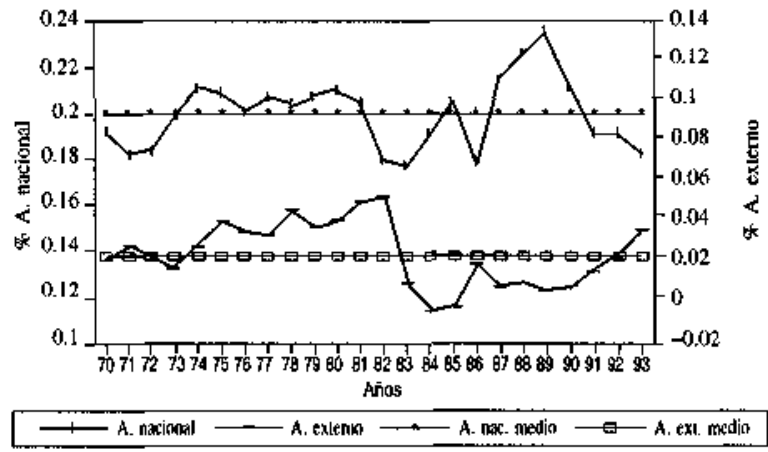

Fuente: CEPAL, sobre la base de cifras oficiales de 15 países.

GRÁFICO 2

América Latina y el Caribe: Indicadores de ahorro privado y ahorro público a precios corrientes

$(\%$ del PIB $)$

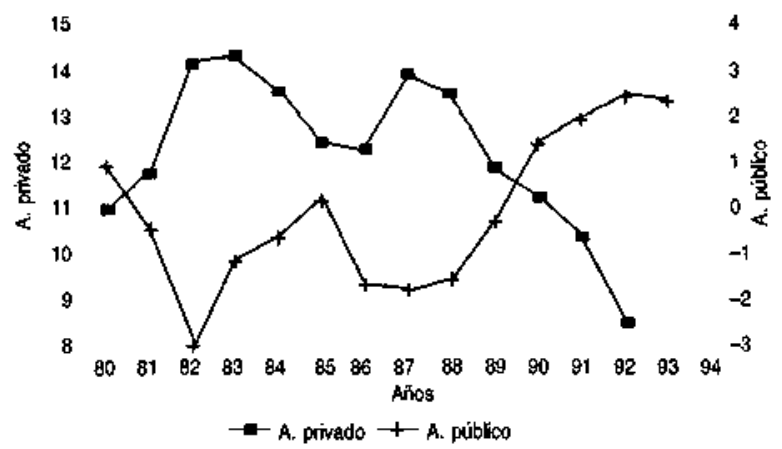

Fuente: CEPAL, sobre la base de cifras oficiales de 11 países. 


\begin{tabular}{|c|c|c|c|c|c|c|c|c|c|c|c|c|}
\hline \multirow[b]{2}{*}{ Países } & \multicolumn{4}{|c|}{$\begin{array}{l}\text { Formación bnuta de capital fijo } \\
\text { (Indices promedio } 1978-1980=100 \text { ) }\end{array}$} & \multicolumn{4}{|c|}{$\stackrel{\text { PIB }}{\text { (Variación promedio anual en el período) }}$} & \multicolumn{4}{|c|}{$\begin{array}{l}\text { Formación bruta de capital fijo } \\
\text { como porcentaje del PlB }\end{array}$} \\
\hline & $\begin{array}{l}1978- \\
1981\end{array}$ & $\begin{array}{l}1982- \\
1984\end{array}$ & $\begin{array}{l}1985- \\
1989\end{array}$ & $\begin{array}{l}1990- \\
1994\end{array}$ & $\begin{array}{l}1978- \\
1981\end{array}$ & $\begin{array}{l}1982- \\
1984\end{array}$ & $\begin{array}{l}1985- \\
1989\end{array}$ & $\begin{array}{l}1990- \\
1994\end{array}$ & $\begin{array}{l}1978- \\
1981\end{array}$ & $\begin{array}{l}1982- \\
1984\end{array}$ & $\begin{array}{l}1985- \\
1989\end{array}$ & $\begin{array}{l}1990- \\
1994\end{array}$ \\
\hline Argentina & 97 & 73 & 67 & 82 & 0.3 & 0.9 & -0.9 & 6.1 & 24.0 & 18.1 & 16.2 & 19.0 \\
\hline Bolivia & 95 & 52 & 68 & 81 & 0.4 & -3.1 & 1.3 & 4.0 & 16.6 & 9.9 & 13.3 & 14.3 \\
\hline Chile & 111 & 82 & 130 & 229 & 7.2 & -3.1 & 6.1 & 5.7 & 17.4 & 14.0 & 17.8 & 22.3 \\
\hline Colombia & 104 & 121 & 128 & 157 & 5.0 & 2.2 & 4.8 & 4.0 & 16.3 & 17.6 & 15.6 & 16.0 \\
\hline Costa Rica & 93 & 61 & 90 & 135 & 2.3 & 1.1 & 3.8 & 4.7 & 24.5 & 16.5 & 21.3 & 24.5 \\
\hline Ecuador & 99 & 79 & 76 & $80^{c}$ & 5.3 & 0.7 & 2.2 & 3.3 & 23.2 & 17.2 & 15.2 & 14.1 \\
\hline El Salvador & 92 & 57 & 72 & $91^{c}$ & -3.2 & -0.9 & 1.5 & 4.2 & 15.2 & 11.2 & 13.3 & 16.6 \\
\hline Guatemala & 100 & 70 & 66 & $85^{c}$ & 3.7 & -2.0 & 2.2 & 3.8 & 13.5 & 9.5 & 8.6 & 9.7 \\
\hline México & 109 & 92 & 86 & 119 & 9.2 & -0.4 & 1.1 & 3.0 & 23.9 & 18.6 & 17.2 & 20.8 \\
\hline Panamá & 108 & 111 & 84 & $120^{F}$ & 8.3 & 1.6 & -1.1 & 6.5 & 21.4 & 18.7 & 13.6 & 17.8 \\
\hline Paraguay & 110 & 102 & 106 & $135^{\mathrm{e}}$ & 10.5 & -0.2 & 4.2 & 2.9 & 25.8 & 21.4 & 19.9 & 21.4 \\
\hline Perú & 109 & 104 & 89 & 89 & 3.9 & -2.3 & -0.2 & 2.8 & 22.9 & 22.0 & 17.6 & 19.7 \\
\hline $\begin{array}{l}\text { República } \\
\text { Dominicana }\end{array}$ & 100 & 87 & 114 & $129^{c}$ & 4.0 & 2.2 & 4.4 & 1.8 & 22.5 & 22.0 & 21.6 & 21.1 \\
\hline Uruguay & 102 & 66 & 49 & 71 & 4.9 & -5.5 & 3.9 & 3.7 & 17.2 & 12.7 & 9.7 & 12.5 \\
\hline Venezuela & 96 & 64 & 55 & 60 & -1.1 & .2 .7 & 1.7 & 3.8 & 29.2 & 20.1 & 15.9 & 16.1 \\
\hline
\end{tabular}

Fuente: CEPAL, sobre la base de cifras oficiales.

En dólares de 1980 .

Coeficiente en moneda constante de cada país.

Promedio años 1990-1993. 
se interrumpió cuando la región nuevamente tuvo acceso a capital externo a comienzos de los afios noventa.

Las variaciones cíclicas del ingreso tienden a tener un impacto positivo pero marginal sobre el ahorro y, por lo tanto, grande sobre el consumo. ${ }^{7}$ Es decir, en la experiencia regional, los cambios bruscos externos 0 internos que generen incrementos "temporales" del ingreso repercuten de manera positiva y significativa en los niveles de consumo, con la consecuente caída en el ahorro nacional.

Esta influencia negativa del nivel de ahorro externo sobre el ahorro nacional es mayor cuando el primero aumenta respecto de su valor de tendencia. ${ }^{8} \mathrm{La}$ respuesta negativa del ahorro nacional a variaciones cíclicas del ahorro externo implica que las formas de insercion en los mercados financieros internacionales inciden de manera importante en los niveles de ahoro nacional.

La sustitución de ahorro nacional por ahorro externo ha sido mayor en aquellos países que, debido al renovado acceso al mercado internacional de capitales a comienzos de los años noventa, han adoptado políticas macroeconómicas que se han traducido en importantes excesos de gasto (en relación con el ingreso nacional) y que han descansado en crecientes apreciaciones cambiarias con fines de estabilización.

La rápida entrada de capitales financieros no ha tenido una contrapartida similar en la creación de activos productivos, produciéndose un efecto "riqueza" como consecuencia de una rápida apreciación en el precio de los activos existentes. Por esta vía, las entradas de capital se tradujeron en mayores tendencias al consumo.

\section{Débil esfuerzo de inversión}

Al inicio de los años ochenta, el coeficiente de inversión medio de la región bordeaba el $23.5 \%$ del PIB. Luego del ajuste ante la crisis de la deuda externa, tal coeficiente cayó a $16.6 \%$ del PIB en 1985 y siguió ca-

\footnotetext{
${ }^{7} \mathrm{E}$ que se ahorre muy poco a partir de los ingresos transitorios sugiere una propensión marginal a consutnir diferente de cero, lo que contradice la hipotesis del ingreso permanente. Si bien la desviación del ingreso de su nivel de tendencia tiene una influencia positiva sobre el ahorro; su coeficiente está en la vecindad de 0.20 , lo que indica que para aumentar el ahotro en un punto porcentual del PrB el ingreso observado debe superar su nivel de tendencia en el equivalente a cinco puntos porcentuales.

${ }^{8}$ Un aumento del ahorro externo de un punto porcentual respecto de su nivel de tendencia reduce el ahorro nacional en alrededor de medio punto porcentual del producto. (CEPAL, 1996a p. 45 y cuadro IV.1).
}

yendo hasta un $15.9 \%$ de tal variable en 1990. De allí en adelante se aprecia una recuperación gradual hasta niveles de $22 \%$ del PIB en 1994-1995, nivel aún inferior al de antes de la crisis. ${ }^{9}$

Las políticas de ajuste y luego de reorientación en la política económica hicieron que las decisiones privadas de inversión dependiesen crucialmente de la estabilidad de las políticas y del grado de certidumbre que enfrentaron los agentes. En ese contexto, la eficacia en el cierre de la brecha externa fue determinante para conseguir la estabilidad macroeconómica y de los nuevos incentivos a la inversión. En la lenta respuesta de los inversionistas a los nuevos incentivos, pueden haber influido secuencias inadecuadas e inconsistencias en la política económica o entre diversas reformas que hayan afectado la estabilidad o predictibilidad de los precios relativos A mayor grado de incertidumbre, mayor será el beneficio de la espera y, por lo tanto, más lenta la respuesta de la inversión ante el mejoramiento de las condiciones macroeconomicas (cuadro 3).

Comparando el período 1978-1981 con el de 1990-1994, se aprecia, para los países de los cuales se tiene información, que la inversión pública como \% del PIB cae en todos ellos de modo significativo, ${ }^{10}$ salvo en Colombia, donde se mantiene, y en Costa Rica, donde la caída es bastante leve.

La caída de la inversión pública, en general, no fue compensada con mayor inversion privada; en Brasil y Venezuela esa caída fue de cuatro y diez puntos, respectivamente."

El financiamiento ordenado del desequilibrio externo constituyó un factor importante en las expectativas de los agentes y disminuyó su grado de incertidumbre. Pocos países consiguieron ya sea apoyo de los organismos multilaterales, como Chile, o transferencias unilaterales de recursos, como Bolivia y Costa Rica; esto les permitió no sólo renegociar Ja deuda con la banca privada internacional, sino además contar con créditos externos para incrementar las importaciones.

\footnotetext{
${ }^{9}$ Colombia, Costa Rica, Chile y El Salvador son los únicos países donde el coeficiente de formación bruta de capital fijo del período 1990-1994 iguala o supera al existente previo a la crisis de la deuda externa.

${ }^{10}$ Las caídas más drắsticas ocumieron en México (6 puntos del pIB, desde 11 a $5 \%$ del mismo), Argentina (4.6 puntos del pri), Brasil y Venezuela ( 3 puntos).

"La inversión privada como \% del pro se duplicó en Chile en el período 1990-1994 respecto de 1978-1981 (de 8.2 a 16.8\%). En similares períodos, los valores recientes superaron a los de antes de la crisis en Costa Rica, El Salvador y México, en este último caso hastn 1994.
} 
En tal sentido, la disponibilidad de financiamiento externo resultó ser un factor significativo en el desempeño de la inversión privada.

A partir de 1991, la tendencia negativa de las variables externas comenzó a revertirse, a raíz de la notable reactivación de las corrientes de capital internacional hacia la región. La consiguiente recuperación registrada en un marco de mayor estabilidad y de mitigación de las restricciones externas contribuyó a elevar los coeficientes de inversión. El aumento, leve en un comienzo, del flujo de inversión extranjera directa y del esfuerzo de ahorro del sector público, también contribuyó al incremento de la inversión.

La profundización del proceso de reforma económica, los adelantos en materia de estabilidad fiscal y de precios y la liberalización de los regímenes de capital extranjero contribuyeron a crear un clima que favoreció la reactivación de las corrientes de inversión extranjera directa (IED).

Hasta los años ochenta, América Latina y el $\mathrm{Ca}$ ribe recibían el grueso de la IED dirigida a los países en desarrollo. Durante los años setenta, la afluencia de IED hacia la región duplicaba con creces la ingresada a los países asiáticos en desarrollo, pero esta situación se invirtió como consecuencia de la crisis de la deuda en la región y del crecimiento acelerado de la IED en dichos países asiáticos a partir de 1986. Así, estos últimos pudieron aprovechar mejor el auge mundial de la IED, que empez 6 en 1987 y aún continúa. ${ }^{12}$

El proceso de reinserción de América Latina y el Caribe en las corrientes de IED ha sido paulatino. Los incentivos (descuentos por conversión de deuda en capital, privatizaciones) desempeñaron un papel muy importante para impulsar el ingreso de esas corrientes a México entre 1986 y 1988 y a Chile entre 1985 y 1990. Después de ese período, los flujos "normales" se restablecieron hasta la crisis de diciembre de 1994 en México y persisten en Chile. Los flujos "normales" han aumentado en forma notoria, si bien se concentran considerablemente por país y sector de destino. ${ }^{13}$

12 Entre 1970-1974 y 1990-1993, la participación de los países asiáticos en desarrollo en los flujos mundiales de IED aumentó de $4.6 \%$ a $14.8 \%$. La de América Latina cayó desde un máximo de $13 \%$ en $1975-1979$, a $6 \%$ en 1985-1989, antes de repuntar a $8.6 \%$ en 1990-1993. En este ámbito, la región aún no recupera la posición relativa que ocupaba antes de la crisis de la deuda.

${ }^{13}$ Hasta 1993, de los siete paŕses sobre los cuales se cuenta con mús información, México y Argentina recibieron más de dos tercios de la EED ingresada a la región ( $37 \%$ y $34 \%$, respectivamente).

\section{Rezagos en empleo y equidad}

A los rezagos sociales acumulados durante la anterior fase de desarrollo se agregaron secuelas de la crisis como la baja de salarios y el aumento del desempleo y de otras formas de subutilización de la fuerza de trabajo. A lo largo de los años ochenta, casi todos los países experimentaron procesos intensos de redistribución regresiva del ingreso, en un contexto de caída en el ingreso por habitante, lo que redundó en un considerable incremento en la pobreza urbana.

El tipo de reestructuración productiva que siguió a los ajustes, los cambios de precios relativos y la liberalización comercial no se han traducido aún en suficiente generación de puestos de trabajo ni en adecuada disminución de las desigualdades. En numerosos parses los indicadores de equidad no han recuperado aún el nivel anterior a la crisis (cuadro 4).

El proceso de modernización productiva está coincidiendo con una acentuación en la heterogeneidad estructural, ampliándose las ya pronunciadas diferencias de productividad entre las empresas grandes y el variado conjunto de las actividades que van quedando rezagadas. La mayor parte de los nuevos puestos de trabajo sigue generándose en sectores de baja productividad y remuneraciones, en tanto se reduce la participación en el empleo de las actividades formales. En evolución paralela, el abanico salarial se ha abierto, en respuesta a los diversos niveles de educación y calificación, y caen los ingresos relativos de trabajadores por cuenta propia, especificamente los no profesionales ni técnicos (CEPAL, 1995d).

El ajuste fiscal de los años ochenta redujo el gasto social y la calidad de las prestaciones (CEPAL, 1994), lo que ha afectado las políticas sociales en su cobertura y eficacia. Del mismo modo, la calidad de estas políticas muestra rezagos, al no haberse readecuado a los desafíos que les plantea el nuevo patrón de política económica.

La nueva modalidad de funcionamiento de las economías de la región muestra tendencias desfavorables en la distribución del ingreso, las que podrían ser transitorias, en tanto se consolida la nueva base productiva y ocupacional. ${ }^{14}$ Sin embargo, no está descartado el riesgo de que más bien correspondan a rasgos

\footnotetext{
${ }^{14}$ Entre las economías que ya funcionan en los nuevos escenarios macroeconómicos y regulatorios y razonablentente cerca de la frontera productiva, solo Colombia (temporalmente) y Uruguay muestran niveles de desigualdad inferiores a los anteriores a la crisis. Chile, con crecimiento elevado y sostenido desde 1985 , muestra reducciones significativas en la pobreza pero grados de desigualdad similares o mayores a los existentes previos a la crisis.
} 
constitutivos de la nueva modalidad de desarrollo. Se trata de tendencias que cabe examinar con atención y que pueden ir requiriendo políticas preventivas o correctoras.

CUADRO

América Latina y el Caribe: indicadores de bienestar en los años ochenta y a comienzos de los novents

\begin{tabular}{|c|c|c|c|c|c|c|c|c|}
\hline \multirow{2}{*}{ País } & \multirow{2}{*}{ Año } & \multirow{2}{*}{$\begin{array}{l}\text { Ingreso } \\
\text { real per } \\
\text { cápita } \\
\text { (índices) }\end{array}$} & \multicolumn{2}{|c|}{$\begin{array}{c}\text { Pobreza } \\
\text { (\% de hogares) }\end{array}$} & \multirow{2}{*}{$\begin{array}{l}\text { Concentración } \\
\text { del ingreso } \\
\text { en áreas urba- } \\
\text { nas (Gini) }\end{array}$} & \multirow{2}{*}{$\begin{array}{l}\text { Utilización } \\
\text { de la fuerza } \\
\text { laborab } \\
\text { (índices) }\end{array}$} & \multirow{2}{*}{$\begin{array}{l}\text { Salario } \\
\text { real } \\
\text { (índices) }\end{array}$} & \multirow{2}{*}{$\begin{array}{c}\text { Gasto } \\
\text { social per } \\
\text { cápita } \\
\text { (índices) }\end{array}$} \\
\hline & & & Nacional & Urbana & & & & \\
\hline
\end{tabular}

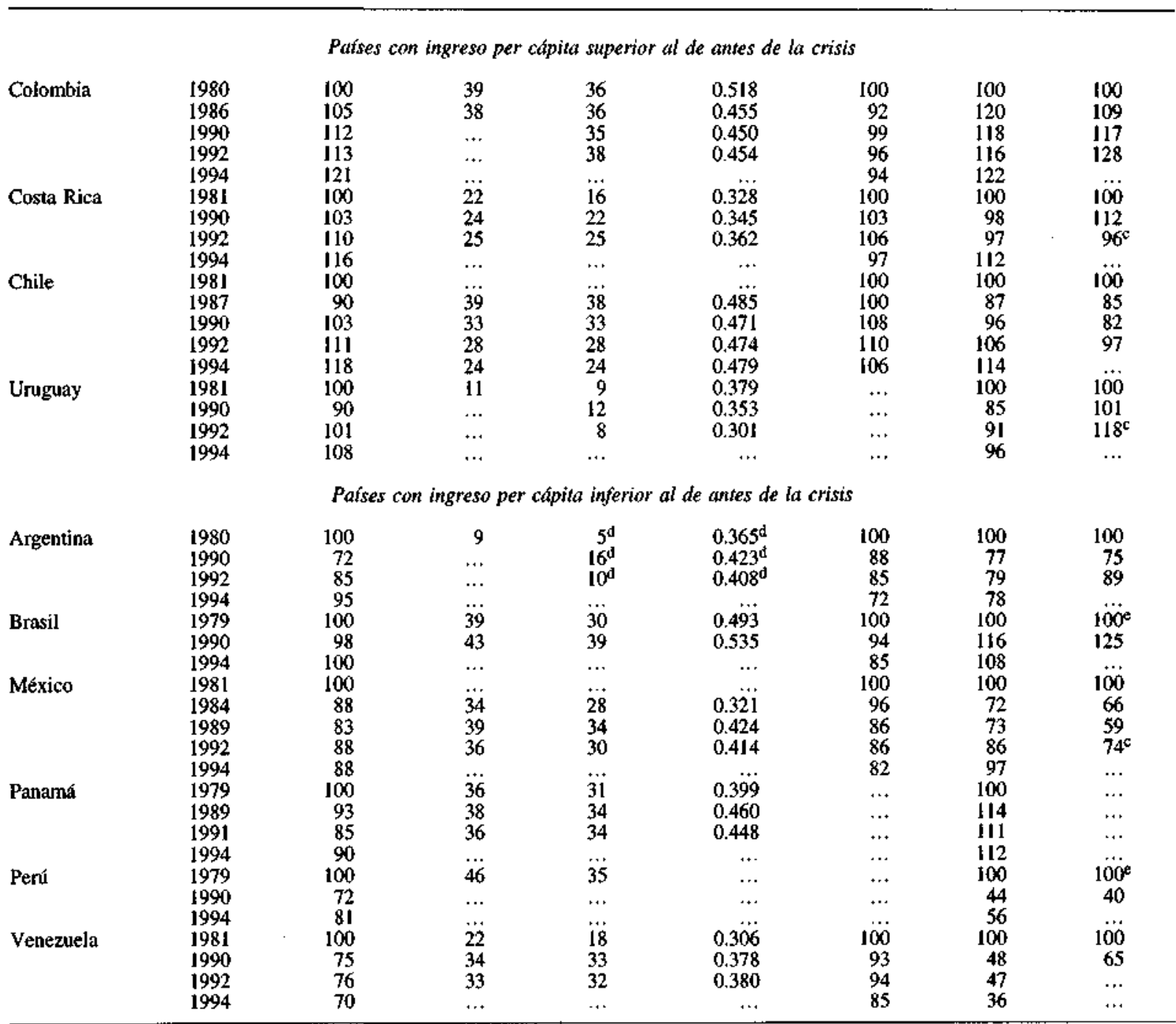

Fuente: CEPAL, sobre la base de cifras oficiales.

a Calculado sobre la base de la distribución del ingreso per cápita entre hogares, por deciles.

b Porcentaje de la fuerza laboral no agtícola empleada en actividades formales.

c 1991 .

d Area metropolitana (Gran Buenos Aires).

e 1980 . 


\section{IV}

\section{Reestructuración productiva y competitividad}

Producto de las reformas económicas y la reanudación de flujos externos, en los años noventa el nivel de actividad de la región se ha elevado a tasas moderadas pero estables, ${ }^{15}$ y los ritmos de crecimiento de los distintos países han ido convergiendo progresivamente. Asimismo, en estos años se ha registrado una gradual recuperación de la inversión - aunque con grandes disparidades entre países-m, una fuerte racionalización productiva en las unidades económicas y un incremento moderado en la productividad total de los factores.

En varios casos, la recuperación de la productividad del trabajo ha sido significativa, si bien a veces ha respondido a una fase del ciclo económico de recuperación o a una drástica reducción del ritmo inflacionario. Es un componente transitorio de la productividad, que no puede proyectarse.

La productividad de la región exhibe un marcado rezago con respecto a los países industrializados y las economías de industrialización reciente (EIR) asiáticas. Es un fenómeno generalizado que se manifiesta en la mayoría de las empresas y sectores, en tecnologías duras y blandas y que, en promedio, se ha intensificado en años recientes.

Si tales rezagos no son abordados, pueden gestarse marcadas diferencias distributivas en la base productiva, virtualmente imposibles de atender con políticas sociales. En tal sentido, las políticas de desarrollo productivo pueden ser un aporte importante para conseguir mejoras en productividad no divorciadas de la equidad.

\section{Lento avance de la productividad}

En el período 1950-1980, América Latina crecío a mayores tasas que los países industrializados, excepto Japón. Sin embargo, tanto la productividad del trabajo como la productividad total de los factores aumentaron menos que en esos países, evidenciando un pe-

\footnotetext{
is En la región, la tasa media de crecimiento anual fue de $3.6 \%$ entre 1990 y 1994. La fuerte desaceleración a sólo $0.6 \%$ en $1995 \mathrm{se}$ debió casi exclusivamente a las recesiones sufridas por Argentina y México, ya que el nivel de actividad del resto de los países de la región aumentó algo más de 4\% (CEPAL, 1995a).
}

ríodo largo de rezago tecnológico. En ese período, el progreso técnico originó sólo una séptima parte del crecimiento de América Latina. ${ }^{16}$

Esta evolución contrasta con la observada en otras regiones, como las ElR asiáticas y los miembros de la Organización de Cooperación y Desarrollo Económi$\cos (\mathrm{OCDE})$, donde la productividad total de los factores no sólo aumentó con más rapidez, sino que continuó haciéndolo, incluso en los años ochenta. En América Latina, durante la época de mayor dinamismo (1950-1973), la tasa de crecimiento de esa productividad fue la mitad de la registrada en las EIR asiáticas y los países de la ocDE. Entre 1950 y 1994, el avance tecnológico contribuyó al crecimiento regional con apenas 0.6 puntos porcentuales anuales, en comparación con 2.8 puntos en el caso de las EIR asiáticas y la $\mathrm{OCDE}^{17}$ (cuadro 5).

La productividad del trabajo aumentó a un ritmo anual cercano a 3\% durante las décadas de 1960 y 1970 , como resultado de la generalizada tendencia a una mayor incorporación de capital en las economías de la región. La tasa retrocedió en los años ochenta, pero en los noventa comenzó a repuntar en algunos países, en especial Argentina y Chile.

La grave desaceleración del crecimiento en los años ochenta conllevó un retroceso de la productividad, debido a la subutilización de los factores productivos. Además de los efectos que el estancamiento económico y la caída de las inversiones ejercieron en la productividad, se amplí la distancia que separaba a la región de la frontera internacional de eficiencia productiva.

En la agricultura, la productividad de la tierra y el trabajo ha mostrado avances importantes en la re-

\footnotetext{
${ }^{16}$ La productividad total de los factores en la región creció a razón de $1.2 \%$ anual entre 1950 y 1980; se estancó entre 1973 y 1980 y cayó en los años ochenta. En el período 1989-1994 registró una leve recuperación $(1.1 \%)$

${ }^{17}$ Del aumento promedio de $4.3 \%$ anual del piB de la región entre 1950-1994, aproximadamente $35 \%$ es imputable al aumento de la cantidad de capital físico, 10\% a mejoras de la calidad de la inano de obra (explicadas principalmente por la elevacion de los niveles educativos), $31 \%$ a incrementos del empleo y sólo $14 \%$ a avances tecnológicos.
} 
CUADRO 5

Amórica Latina (6 países): comparación internacional del crecimiento y de la productividad total de los factores, 1950-1994

(Tasas medias de variación anual)

\begin{tabular}{|c|c|c|c|c|c|c|c|c|}
\hline \multirow[t]{2}{*}{ Países } & \multicolumn{2}{|c|}{ Producto intemo bruto ${ }^{a}$} & \multicolumn{2}{|c|}{$\begin{array}{l}\text { Productividad del } \\
\text { factor trabajo }\end{array}$} & \multicolumn{2}{|c|}{$\begin{array}{l}\text { Productividad del } \\
\text { factor capital }\end{array}$} & \multicolumn{2}{|c|}{$\begin{array}{l}\text { Productividad total } \\
\text { de los factores }{ }^{b}\end{array}$} \\
\hline & $1950-1980$ & $1989-1994$ & $1950-1980$ & $1989-1994$ & $1950 \cdot 1980$ & $1989-1994$ & $1950-1980$ & $1989-1994$ \\
\hline América Latina & 5.3 & 4,0 & 3.6 & 3.7 & 6.2 & 2.3 & 1.2 & 1.1 \\
\hline Argentina & 3.8 & 6.1 & 2.1 & 2.3 & 4.9 & 0.8 & 1.0 & 4.5 \\
\hline Brasil & 7.0 & 0.9 & 4.4 & 2.8 & 9.8 & 2.3 & 1.2 & -1.6 \\
\hline Chile & 3.4 & 6.4 & 1.8 & 4.1 & 4.0 & 4.7 & 1.1 & 2.5 \\
\hline Colombia & 5.1 & 4.3 & 3.6 & 4.0 & 4.1 & 3.5 & 1.7 & 0.8 \\
\hline México & 6.5 & 3.0 & 4.4 & 3.7 & 7.7 & 2.4 & 1.5 & 0.1 \\
\hline Venezuela & 5.9 & 3.6 & 5.2 & 5.5 & 6.6 & 0.2 & 0.7 & 0.3 \\
\hline Países asiáticos & 7.7 & 7.6 & 5.0 & 1.5 & 6.7 & 7.4 & 2.6 & 4.4 \\
\hline Japón & 8.0 & 3.8 & 1.8 & 1.7 & 8.7 & 10.5 & 4.3 & -0.4 \\
\hline \multicolumn{9}{|l|}{ Resto de países } \\
\hline 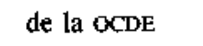 & 4.1 & 1.7 & 0.1 & 0.5 & 5.5 & 3.0 & 2.4 & 0.5 \\
\hline Estados Unidos & 3.3 & 1.7 & 1.7 & 0.9 & 3.3 & 2.2 & 1.3 & 0.5 \\
\hline
\end{tabular}

Fuente: CEPAl, sobre la base de estimaciones de Hofman, "Economic growth and fluctuation in Latin America. The long run", documento presentado en la conferencia "Development Strategy After Neoliberal Economic Restructuring in Latin America", Miami, Centro Norte-Sur/ Universidad de Miami, 1995; y Capital stock in Latin America: a 1994 update, Cambridge Journal of Economics, por aparecer.

${ }^{a}$ En dólares a precios de 1980.

b En el factor trabajo se incluyen los aumentos del promedio de años de educación.

gión, ${ }^{18}$ pero aún dista considerablemente de la que se registra en Europa, Estados Unidos, Canadá y Japón. La productividad de la fuerza de trabajo agrícola alcanza a un tercio de la de Europa y apenas a $7 \%$ de la de Estados Unidos/Canadá. Esta diferencia, lejos de ir disminuyendo, se amplió en el período 1970-1990, sobre todo en el caso de la productividad laboral, y algo menos en el de la productividad por hectárea. ${ }^{19}$

La industria minera mundial muestra una tendencia hacia una mayor concentración de la propiedad, con un aumento de la presencia de las grandes compañías transnacionales y un redespliegue parcial de éstas hacia zonas en desarrollo. Esto, sumado a las ventajas naturales mineras y la promoción de las inversiones ex-

${ }^{18}$ Los desempeños agrícolas más destacables corresponden a las oleaginosas, soja y girasol, aunque también mostraron buenos resultados varios de los demás productos básicos, como came, maíz, hortalizas y frutas.

${ }^{19}$ Entre las causas que explican este rezago relativo se encuentran el bajo uso de fertilizantes y de semillas mejoradas, el reducido nivel de mecanización y, particularmente, las marcadas heterogeneidades en el acceso a la tierra, riego y crédito. tranjeras, ha ido favoreciendo que en la gran minería de la región el nivel tecnológico avance a la par con la frontera mundial en estas áreas, incluyendo una mayor preocupación por procesos ambientalmente sustentables. ${ }^{20}$

Derivado de ello, el sector minero de la región ha exhibido un desempeño positivo desde tres puntos de vista fundamentales: la evolución de la producción física, la participación de la región en la producción mundial y el desarrollo tecnológico. ${ }^{21}$ Esta tendencia está reflejándose en un aumento del grado de procesamiento local de los productos mineros y en una mayor articulación productiva interna, con notorios efectos multiplicadores en la generación de valor agregado.

\footnotetext{
20 Entre las causas de tal redespliegue se encuentran el agotamiento de las reservas de calidad en zonas industrializadas, la progresiva declinación en los precios internacionales de los principales productos mineros y las mayores exigencias anbientales en la OCDE. ${ }^{21}$ Destacan aquí particularmente los casos del cobre, estaño, hierro, plata y zinc.
} 
La productividad manufacturera está evolucionando en forma positiva. Ya en la segunda mitad de los años ochenta su crecimiento se había acelerado a ritmos incluso superiores a los del decenio anterior. Aún así, en los años noventa los aumentos de productividad han alcanzado tasas sin precedentes en los dos decenios anteriores, si bien el desempeño de la industria mediana y grande en las economías de mayor tamaño ha influido fuertemente en estos resultados.

Esta mejoría se sustentó, en parte, en una mayor utilización de la capacidad instalada y, sobre todo, en cambios en la organización productiva. Es decir, ese dinamismo se logró con relativamente pocas inversiones nuevas y un considerable cambio técnico, de carácter "desincorporado" (no directamente vinculado a la incorporación de nuevos bienes de capital, aunque ello implique inversiones complementarias), lo que redund 6 en una caída del empleo.

\section{Se amplian las brechas internas de producti- vidad}

Durante los años ochenta el aumento de la heterogeneidad estructural se reflejo sobre todo en fuertes caídas de la productividad laboral en el sector de los servicios. Una gran parte de la fuerza de trabajo afectada por el proceso de precarización del empleo que se observó durante ese período buscó refugio en el sector terciario, realizando actividades de baja productividad.

En la actual fase se perciben señales de un aumento de la concentración económica y de la heterogeneidad estructural, que se manifiesta en elevadas y persistentes diferencias intrasectoriales de productividad.

La productividad de las actividades de cultivo y ganaderas, realizadas predominantemente por pequeños y medianos productores en ecosistemas de clima templado, se aproxima a la de sus equivalentes en países desarrollados. Asimismo, en la agricultura comercial de la región surgen modernos sistemas de agronegocios, que representan una nueva forma de internacionalización. En cambio, en cultivos característicos de la agricultura de subsistencia y difundidos en sistemas agroecológicos muy diversos, las diferencias de productividad con respecto a los niveles internacionales son enormes.

En el sector minero, el dinamismo no es compartido por las pequeñas y medianas empresas, que muestran un creciente rezago tecnológico respecto de la gran minería situada en la frontera tecnológica internacional. En el sector manufacturero, el acelerado aumento de la productividad en los años noventa se ha centrado en las industrias medianas y grandes, ampliándose el desnivel con las pequeñas y con las microempresas, responsables del grueso del empleo industrial. En e] sector terciario, las telecomunicaciones y los servicios financieros están siendo objeto de profundas reestructuraciones en muchos países de la región, lo que se traduce en fuertes aumentos de productividad en esas actividades. En algunos casos, como los de Argentina, Colombia y Chile, ello ha contribuido a mejorar considerablemente la productividad laboral media del sector terciario. Sin embargo, lo más frecuente es que el aumento del empleo en el conjunto del sector siga apoyado en la expansión de las actividades de menor productividad (trabajadores por cuenta propia, no profesionales ni técnicos, microempresas). La coexistencia en muchos países de una corriente de fuerte modernización en algunas actividades terciarias con otra de expansión de actividades informales indica que las diferencias de productividad dentro de este sector tienden a ampliarse.

Al comparar las variaciones de la productividad del sector secundario en su conjunto (minería, indus. tria y construcción) entre 1990 y 1993 con las tasas de aumento de la productividad en las empresas industriales grandes y medianas, se comprueba que las primeras son bastante inferiores a las segundas. Si se consideran además los destacados incrementos en la gran minería, es posible concluir que en el período, la productividad del trabajo en la pequeña y mediana industria, la construcción y probablemente la pequeña minería, ha sufrido una baja significativa.

Por otra parte, se comprueba una mayor concentración de la actividad productiva en empresas pertenecientes a grandes conglomerados, nacionales o transnacionales. Esta situación se vincula en parte a la mayor densidad de capital que implica el mayor dinamismo de las industrias de productos básicos, pero también a la concentración de vastos recursos financieros, la realización de ganancias de capital y la captación de nuevas cuasi rentas por parte de un reducido número de grandes conglomerados empresariales multisectoriales, que emergieron en la mayoría de los países durante los procesos de ajuste y reforma estructural y que, en varios casos, se beneficiaron de procesos de privatización que no preservaron adecuadamente la competencia.

\section{Cambios sectoriales}

La recuperación registrada en los años noventa la 
compartieron, en general, todos los sectores. ${ }^{22}$ Entre los productores de bienes transables, destaca el desempeño de la minería, mientras que las actividades de producción no transable, como la energía, la construcción y el transporte, exhibieron desempeños ampliamente superiores al del conjunto de la economía. La industria manufacturera perdió participación relativa en el producto en favor de actividades basadas en recursos naturales, y de bienes y servicios no transables.

La mayor propensión a introducir progreso técnico ha estado más vinculada a la explotación de recursos naturales, en particular en la minería pero también en las demás actividades primarias. La incorporación de tecnología ha sido intensa en toda la cadena de distribución agrícola, que incluye empaque, cadena de frío y embarque, entre otras etapas, así como en las actividades pesqueras, las forestales y en la actividad turística en el Caribe.

La reestructuración del sector industrial muestra un desplazamiento desde un patrón de especialización basado en el complejo metalmecánico ${ }^{23}$ a otro que se apoya gradualmente en las ramas industriales con alta densidad de recursos naturales. Si bien no se trata de ramas productivas enteramente nuevas, en la segunda mitad de los años setenta y en los ochenta aparece en ellas una nueva generación de plantas fabriles con alto grado de modernización, mayor coeficiente de capital y vigorosa actualización tecnológica (aluminio, petroquímica, celulosa y papel, hierro y acero, metales no ferrosos, alimentos). Estas plantas fabriles son de proceso productivo continuo, regulado por la tecnología de procesos (machine-paced) y, en comparación con la industria metalmecánica, hacen menor uso de mano de obra, ingeniería de organización y métodos de producción.

Además de la menor presencia relativa de la actividad metalmecánica, esta tendencia tiene como contrapartida un retroceso de la producción textil y del cuero y calzado. También se observan contracciones en el caso de actividades productivas con alto valor

${ }^{22}$ La excepción más notable la constituyen los servicios sociales y comunales, cuyo nivel de actividad se rezagó considerablemente debido a la contención del gasto fiscal corriente y la racionalización del empleo público.

${ }^{23}$ El complejo metalmecánico abarca un conjunto de industrias con predominio de subprocesos técnicos de producción y montaje de partes, piezas y subconjuntos metálicos. Todas estas tareas requieren uso intensivo de mano de obra, recursos bumanos calificados, servicios de ingeniería y de organización y métodos de producción. Se trata de industrias dedicadas a la fabricación de bienes de consumo durables, automóviles, bienes de capital relativamente sencillos, como motores y calderas, y equipo agricola y para la industria de alimentos, entre otros. agregado y uso intensivo de ingeniería de planta, como la industria de bienes de capital y la química fina.

El aumento de la disponibilidad y la calidad de los recursos naturales ha inducido una rápida expansión relativa de las industrias que los procesan. Por lo general, la actividad de estas nuevas plantas industriales se ha limitado a las fases iniciales de procesamiento, sin avanzar hacia un mayor valor agregado nacional y la elaboración de productos especiales (como papeles finos, aceites hidrogenados o con bajo colesterol, aceros especiales, perfiles de aluminio, café soluble y aleaciones de cobre, entre otros), tarea que tiende a quedar en manos de los compradores externos.

\section{Reestructuración empresarial}

En cada país ha surgido un grupo de empresas - reducido en número, pero importante en la generación del PIB- que muestran una reacción "proactiva", es decir, que han asumido de manera dinámica las nuevas condiciones del entorno, y han transformado significativamente sus procedimientos operativos y expandido sus inversiones y su capacidad de producción, a partir de nuevas plantas fabriles y modelos de organización del trabajo. Un segundo grupo de empresas ha reaccionado de manera "defensiva", adaptándose al nuevo escenario mediante cambios menores, referidos a organización, subcontratación o abastecimiento externo (outsourcing) y desarticulación vertical, pero sin incurrir en grandes inversiones ni expandir muy significativamente su capacidad instalada. Un tercer grupo de empresas, mayoritario en número pero con menor participación relativa en el PIB, no ha contado con la capacidad, la información o los recursos que requiere un proceso de adaptación, lo que ha conducido a la desaparición de algunas y provocado un profundo decaimiento relativo en otras.

En el caso de las filiales de empresas manufactureras transnacionales, una gran mayoría de estas empresas optó por estrategias de racionalización defensiva, es decir, basadas en tecnologías de información y gestión, reducción de gastos y empleo, y suspensión de inversiones adicionales significativas (Mortimore, 1995).

Los desajustes macroeconómicos de los años ochenta dieron origen a señales que indujeron a los agentes económicos a privilegiar más lo financiero y lo especulativo que lo tecnológico. La incertidumbre sobre el grado de consolidación de las reformas económicas dio primacía a las decisiones de corto plazo y discriminó en contra de las inversiones de madura- 
ción más lenta o con mayor riesgo e incertidumbre. Con ello, disminuyeron las inversiones en tecnologías y equipos modernos relacionadas con el diseño de nuevos productos y la actividad de investigación y desarrollo.

Tanto por razones de ventajas competitivas, más evidentes ante la reorientación en la estrategia de desarrollo, como por incorporación de tecnología, los sectores que procesan recursos naturales y los productores de bienes industriales básicos de amplio uso, quedaron en una situación de privilegio en el nuevo cuadro de incentivos macroeconómicos.

\section{Reformas institucionales y modernización de los servicios}

Los procesos de apertura comercial, desregulación de mercados, privatización y apertura a la inversión extranjera, así como la dinámica del avance de la tecnología y las formas de organización empresarial, están generando cambios institucionales que obligan a actualizar las categorías analíticas convencionales respecto de bienes y servicios transables y no transables, así como respecto de bienes y servicios para asegurarse de que ellas sigan siendo pertinentes.

La exportación de servicios financieros, de ingeniería y consultoría ha transformado en transables muchos servicios que hasta hace poco no lo eran. Asimismo, la movilización de recursos financieros, en algunos casos provenientes de fondos de pensiones o de emisiones de bonos y acciones en el mercado local o internacional, ha favorecido la profundización del mercado de capitales y, en ocasiones, las inversiones nacionales en economías vecinas. Las recientes privatizaciones de servicios públicos de energía y telecomunicaciones han contribuido a desencadenar un importante proceso de inversiones productivas que ha dinamizado estos sectores y también los de la construcción y el transporte.

La tendencia actual a la subcontratación o abastecimiento externo (outsourcing) de servicios aumenta las transacciones registradas entre el sector de los servicios y los demás sectores del sistema productivo y fortalece los mercados en que se realizan esas transacciones. Se da así origen a servicios que operan a escala industrial.

La producción de bienes primarios e industriales básicos de exportación impone grandes exigencias de infraestructura vial, portuaria y de comunicaciones, lo que ha contribuido a que el crecimiento medio del sector del transporte, almacenamiento y comunicaciones haya duplicado el del PIB a partir de 1980. Igual sucedió con el sector de la electricidad, gas y agua, que desde ese mismo año se ha mantenido como uno de los más dinámicos, resultado que refleja tanto las necesidades de energía de las nuevas actividades productivas basadas en recursos naturales como el descubrimiento de nuevas fuentes de energía no renovable.

Las privatizaciones y la desreglamentación de mercados internos configuran un nuevo escenario en el que los agentes privados y las políticas públicas interactúan y las instituciones encaran desafíos emergentes en materia de regulación y promoción de la competencia.

El proceso de privatización ha abarcado sectores muy diversos. Partió por un conjunto de empresas dispares ubicadas en mercados competitivos, para luego incorporar industrias, servicios financieros, empresas de transporte y otras vinculadas a los recursos naturales. Más recientemente, la privatización se ha ido extendiendo hacia los servicios de utilidad pública y actividades de infraestructura.

Las experiencias de privatización en América Latina han diferido en cuanto a secuencia, velocidad, intensidad, cobertura sectorial y mecanismos de traspaso utilizados. El proceso ha sido generalizado en el caso de empresas que operan en mercados competitivos y de relativa magnitud en los sectores del transporte y la agroindustria. Las privatizaciones previstas para los próximos años apuntan claramente hacia los servicios de utilidad pública y las actividades de infraestructura. Así, por ejemplo, está contemplado realizar privatizaciones o asociarse con agentes privados, bajo modalidades de concesión o similares, en las áreas de la energía (Bolivia, Brasil, Colombia, Costa Rica, Ecuador, El Salvador, México, Panamá, Paraguay y Venezuela); las telecomunicaciones (Bolivia, Brasil, Costa Rica, Ecuador, El Salvador, Guatemala, Hon* duras y Panamá); la infraestructura portuaria o vial (Brasil, Chile, Colombia, Ecuador, El Salvador, Guatemala, México, Panamá, Perú y Venezuela) y el abastecimiento de agua potable (Brasil, Ecuador, El Salvador, Honduras, México, Panamá, Paraguay y Venezuela). Menos evidente es el énfasis en los servicios financieros, el transporte y los recursos naturales. ${ }^{24}$

24 Entre los hechos recientes más destacados figuran la implementación parcial del proceso de capitalización en Bolivia, que se espera canalice inversiones equivalentes a casi $30 \%$ del PIB en los próximos siete años; en Brasil, privatizaciones parciales en telecomunicaciones, distribución de gas natural, hidrocarburos y servicios navieros; en México, privatizaciones en transporte, telecomunicaciones, gas natural e infraestructura; $y$ en Chile, mecanismos de concesión en infraestructura, distribución de gas natural y empresas sanitarias, incluido el tratamiento de aguas servidas. 


\section{Competitividad y exportaciones}

Las exportaciones agropecuarias de la región siguen concentrándose en productos de lenta evolución en el comercio mundial. Si bien es cierto que la existencia de notables excepciones demuestra una gran capacidad para insertarse en nuevos nichos de mercados, la región ha perdido participación en el comercio mundial de productos agropecuarios. Dicha proporción, que entre 1980 y 1985 alcanzaba a cerca de $15 \%$, había bajado a $11.2 \%$ en 1993 .

Entre las ventas externas más dinámicas del sector agropecuario figuran las exportaciones forestales, nuevos productos de exportación, como fruta fresca y hortalizas, y exportaciones de un mismo bien bajo una mayor diversidad de formas - fresco, refrigerado, congelado- en respuesta a las distintas necesidades de los mercados consumidores, o con mayor grado de elaboración. Todos estos muestran notorio dinamismo entre las exportaciones que la región realiza a la $O C D E$.

Las actividades mineras en América Latina han entrado a una fase muy dinámica favorecida por las reformas en la legislación minera, lo que ha reforzado la complementariedad entre los rendimientos superiores a la media mundial de los yacimientos mineros de la región y la sincronización de la gran minería regional con el progreso técnico internacional; esto permite un aprovechamiento más intenso de las rentas potenciales de estos recursos. Se prevé un nuevo ciclo de inversiones mineras que ampliará la oferta exportable de la región. ${ }^{25}$

Desde finales de los años setenta, el volumen de las exportaciones manufactureras creció notablemente (alrededor de 7\% anual), aun cuando la producción de estos bienes permaneció prácticamente estancada. Este resultado revela que el sector externo se convirtió en el componente más dinámico de la demanda y, al mismo tiempo, que muchas empresas han sido capaces de reorientar su producción hacia los mercados externos.

Las exportaciones industriales, que habían desempeñado un papel muy importante en los años ochenta, continuaron expandiéndose en los noventa, tanto en volumen como en valor, a pesar de la caída de precios que sufrieron muchos insumos básicos exportados por la región (cobre, celulosa y harina de pescado, entre otros). Al mismo tiempo, las importaciones industriales, que se habían reducido considerablemente en la primera mitad de la década de 1980 , volvieron a crecer con fuerza a partir de entonces. Como resultado, el balance comercial ligeramente positivo que liegó a registrar el sector manufacturero en 1985 , se volvió negativo en 1990 y empeoró mucho más en los años siguientes, siendo el déficit superior al de $\mathbf{1 9 8 0}$.

La situación del sector industrial a mediados de los años noventa se caracteriza por una renovación cada vez más generalizada de su capacidad de crecimiento, incrementos de productividad, mayor capacidad exportadora que en décadas anteriores, fuerte expansión de las importaciones de manufacturas y un considerable balance negativo en el comercio manufacturero.

Los países de América Latina agrupados en la Asociación Latinoamericana de Integración (ALADI) han modificado la estructura de sus exportaciones a la OCDE en la dirección apropiada (la contribución de las manufacturas se duplicó, de $23 \%$ a $48 \%$, y la de las manufacturas no basadas en recursos naturales prácticamente se triplicó entre 1980 y 1993). Sin embargo, su participación en las importaciones totales de los países de la OCDE mostró un leve descenso (de $4.4 \%$ a $4.1 \%$ ) y la posición competitiva de los sectores dinámicos sólo registró avances limitados entre 1980 y 1993 (de $1.9 \%$ a $2.7 \%$ las manufacturas y de $1.3 \%$ a $2.4 \%$ las manufacturas no basadas en recursos naturales) (Mortimore, 1995).

La posición competitiva de América Latina y el Caribe muestra claros rezagos comparada con la de los países asiáticos en desarrollo. Si bien la estructura de sus exportaciones registró cambios significativos en favor de las manufacturas de mayor demanda, su participación en las importaciones de la OCDE, sobre todo en los rubros más dinámicos, ha mostrado avances limitados. Las excepciones más notables son la industria automotriz de México y las de las zonas francas (maquiladoras) de México y la República Dominicana. En ambos casos, las empresas transnacionales han desempeñado un papel importante (cuadro 6).

${ }^{25}$ La inversión comprometida en la región en el resto de los affos noventa asciende aproximadamente a 14000 milliones de dólares,

cerca de un tercio del total de la inversion minera mundial en el período. 
CUADRO 6

América Latina y el Caribe: Competitividad internacional, 1980 y 1993 (Porcentajes)

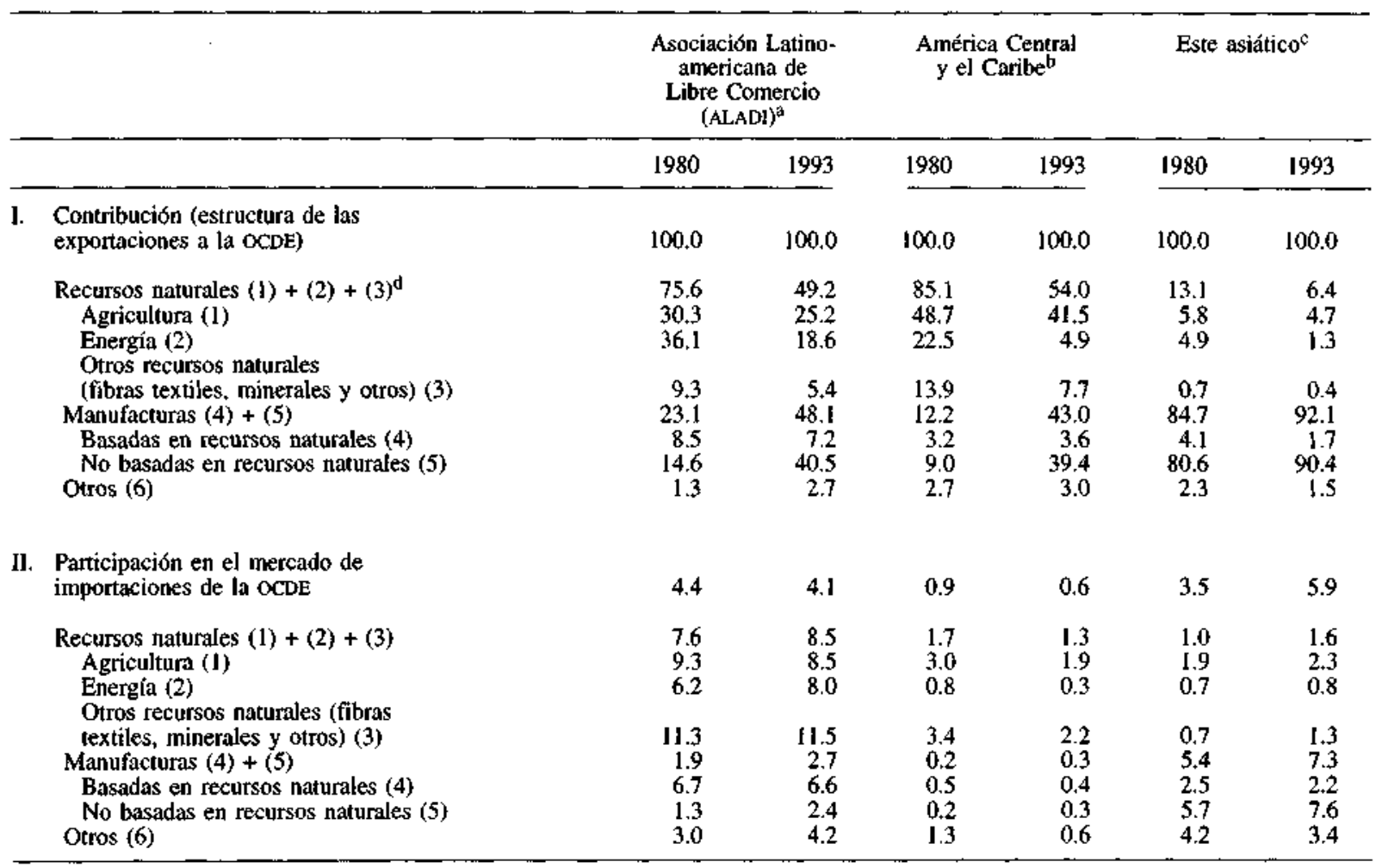

Fuente: CEPAL, sobre la base del programa de computación CAN, Análisis de la competitividad de fos países, versión 2.0 .

argentina, Bolivia, Brasil, Chile, Colombia, Ecuador, México, Perú, Paraguay, Uruguay y Venezuela.

b Costa Rica, El Salvador, Guatemala. Honduras, Nicaragua, Barbados, Cuba, República Dominicana, Haiti, Jamaica y Trinidad y Tabago.

c Corea del Sur, Hong Kong, Singapur y la provincia china de Taiwán.

d En este cuadro los números entre paréntesis significan to siguiente:

(1) Secciones 0, 1 y 4; capítulos $21,22,23,24,25$ y 29 de la Clasificación Uniforme para el Comercio Internacional (Revisión 2).

(2) Sección 3.

(3) Capítulos 26,27 y 28.

(4) Capítulos 61, 63 y 68; grupos 661, 662, 663, 667 y 67I.

(5) Secciones 5, 6 (menos capítulos y grupos incluidos en el 4), 7 y 8 .

(6) Sección 9.

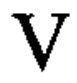

\section{Políticas para fortalecer el desarrollo}

Los objetivos de las políticas públicas en la región reflejan el interés por acercarse a una institucionalización progresiva de economías de mercado abiertas, estables y competitivas, con correcciones en la situación social y en un marco de profundización democrática.

Tal complejo proceso se refleja también en un tránsito hacia nuevas estructuras productivas, entendi- das éstas como la interacción de empresas, agentes productivos, mercados, políticas sectoriales e instancias de regulación. En ese proceso destaca la rapidez con que cambiaron las reglas del juego y la lentitud con que se readecuan las organizaciones. Persisten comportamientos de economía cerrada y reducida flexibilidad institucional para abordar los desafíos de competitividad; en particular, buena parte de las em- 
presas muestra marcados rezagos en la adopción de normas de calidad, innovación tecnológica, capacitación de la mano de obra, persistiendo en ellas relaciones industriales de escasa colaboración. Por su parte, el sector público resiste su modernización, no abandona prácticas excesivamente burocráticas y, en general, sus políticas no están sujetas a evaluación y sus recursos se asignan sin criterios de desempeño.

La recuperación gradual del crecimiento y los avances en competitividad coexisten con una ampliación de las brechas internas de productividad, lo cual resta dinamismo al crecimiento, y limita las posibilidades de empleo y de mayor equidad.

De allí la importancia de un enfoque que persiga avances en estabilidad, competitividad y equidad, integrando de un modo articulado los temas macroeconómicos, microeconómicos e institucionales. Ello no significa bajarle el perfil a la macroeconomía sino entenderla como requisito previo insustituible, pero no suficiente de la transformación productiva. Se la debe complementar con el desarrollo de mercados a fin de que los incentivos creados en el plano macroeconómico se transformen en acciones concretas para estimular la productividad, la innovación y la difusión tecnológicas, reduciendo la heterogeneidad del crecimiento y mejorando la distribución de sus resultados.

\section{Elevar la tasa de crecimiento}

Si bien es cierto que la región ha conseguido crecer al $3.6 \%$ entre 1990 y 1995 , dicho ritmo es claramente insuficiente desde la doble optica de superar los rezagos en equidad y de reforzar la incorporación de progreso técnico. Es un ritmo que, además de ser notoriamente inferior al conseguido entre 1950 y 1980 , congela la situación de pobreza en la región.

La CEPAL estima que para alcanzar niveles aceptables de empleo y productividad se requiere una expansión del PIB cercana al $6 \%$ anual, con incrementos en el PIB por habitante en torno al $4 \%$ anual.

El objetivo de crecimiento elevado y estable exige mayores esfuerzos de ahorro e inversión, ya que para crecer al $6 \%$ anual es preciso elevar significativamente la inversion, llevando el promedio regional desde un $22 \%$ a un $28 \%$ del PIB, con una adecuada combinación de ahorro nacional y externo que permita financiarlo de modo compatible con la estabilidad macroeconómica.

Aproximarse gradualmente a tasas de crecimiento de $6 \%$ y de ahorro nacional cercanas al $25026 \%$ del PIB - y por lo tanto con un ahorro externo de alre- dedor de 2 a $3 \%$ del PIB- es una propuesta exigente pero posible de alcanzar. En todo caso, ella no es más que un ejercicio que ilustra rangos y no cifras específicas, pues el acentuado cambio en el contexto economico dificulta la extrapolación de períodos historicos. ${ }^{26}$

\section{Consolidar las reformas económicas}

La preservación de los equilibrios macroeconómicos básicos es insustituible en el fortalecimiento del desarrollo, mostrándose relevantes al respecto una visión de conjunto que vele simultáneamente por una inflación baja y declinante, con avances en estabilización apoyados en austeridad fiscal, incrementos en ahorro interno, inversión y productividad, preservando rangos sustentables de déficit en cuenta corriente y un nivel competitivo para el tipo de cambio real.

La gestión macroeconómica debe privilegiar la promoción del ahorro nacional y lograr que el ahorro externo y el interno sean complementarios, accediendo a niveles estables de ahorro externo y orientando ambos al financiamiento de un mayor nivel de inversión y productividad. Ređucir la inflación, favorecer el ahorro público y privado, atraer los capitales externos de largo plazo, y velar porque las señales de precios relativos privilegien factores permanentes y favorezcan la inversión en bienes transables, son desafíos permanentes a la consistencia de la gestión macroeconómica orientada a favorecer la transformación productiva.

Junto con valorar la afluencia de capitales externos hacia la región, es necesario destacar la relevancia del dilema que las autoridades económicas enfrentan para garantizar simultáneamente la estabilidad macroeconómica, la persistencia de la afluencia de capitales externos, su complementación con el ahorro nacional y su canalización hacia la inversión productiva.

Conjugar políticas fiscales cambiarias y monetarias, en un contexto de creciente liberalización de los mercados, impone el desafío de evitar revaluaciones de la moneda que no guarden relación con los equilibrios externos de largo plazo. La forma como hacerlo, sin embargo, admite diversas respuestas, de acuerdo a

\footnotetext{
${ }^{26}$ En particular, debiera esperarse que las reformas económicas conduzcan a una mayor eficiencia de la inversión, que permita obtener un mayor ritmo de crecimiento con un determinado nivel de inversión. Esto, sin embargo, no es mecánico y depende crucialmente de avances en la eficiencia de la intermediación financiera.
} 
las particularidades del ciclo macroeconómico y del patrón de política económica. Del mismo modo, hay coincidencia en fortalecer el ahorro nacional, pero matizada respecto de las formas concretas de abordar las políticas de apertura de la cuenta de capitales y la intervención pública en los mercados cambiarios y monetarios. En fin, es preciso un examen más atento de las especificidades macroeconómicas e institucionales de cada realidad nacional ya que, junto con el indispensable incremento de las tasas de ahorro, las posibilidades de complementar éste con ahorro externo, regulando los flujos de capital extranjero, están estrechamente condicionadas a tales especificidades.

De allí la pertinencia del análisis que vincula los aspectos macroeconómicos, microeconómicos e institucionales para el examen de las políticas públicas y su readecuación a los desafíos externos e internos. Este instrumento es útil para atender a los diferentes estadios de desarrollo y las diversas realidades nacionales que muestran los países de la región, enriqueciendo el examen comparativo y evitando generalizaciones excesivas. Con todo, las particularidades nacionales no deben ocultar que el contexto macroeconómico debiera manifestarse en relativa estabilidad de precios, tipos de cambios verosímiles, tasas de interés real positivas pero moderadas y más crecimiento liderado por las exportaciones.

La experiencia empieza a mostrar que existe un fuerte grado de complementariedad entre políticas macroeconómicas, de desarrollo productivo y de promoción de la competencia. De una parte, los deterioros sostenidos en el tipo de cambio real pueden anular los esfuerzos de fomento de la tecnología, la productividad y la capacitación, reduciendo la competitividad. Por otra parte, los procesos de privatización pueden mejorar la competitividad, al privilegiar el apoyo a mercados competitivos, fortaleciendo la regulación de mercados que se caracterizan por el predominio de mercados naturales. Estos son campos relevantes de las reformas económicas en curso y merecen mayor atención que la que están recibiendo.

\section{Ahorro, inversión y financiamiento}

Conseguir un acercamiento gradual a tasas de crecimiento sostenido en torno al $6 \%$ anual requiere tasas de inversión cercanas al $28 \%$ del PlB, con la productividad y composición actual del capital. Ello significa un incremento de 5.5 a 6 puntos respecto del actual coeficiente medio de inversión.

En tal contexto de crecimiento ciertamente aumentaría el ahorro nacional; sin embargo, de hacerlo conforme al comportamiento de las últimas dos décadas, el incremento sería insuficiente, ya que sólo se pasaría del 18 al $23 \%$ del piB. La diferencia, poco más de $5 \%$ del PIB, debería ser cubierta con ahorro externo. Una de las lecciones de la crisis mexicana es justamente la de evitar apoyos excesivos en el ahorro externo, particularmente si se trata de recursos de corto plazo. Siendo razonable que el estado actual de las reformas económicas en la región garantice un acceso estable y más ordenado al financiamiento externo que en los años ochenta, es también evidente que déficit en cuenta corriente del 5\% del PIB trascienden los límites de la prudencia macroeconómica y seguramente terminarian afectando severamente las posibilidades de crecimiento estable.

De allí la necesidad de apoyarse básicamente en ahorro nacional, el que debiera elevarse a un rango parecido al $25 \%$ del P]B, es decir, un salto de 5 a 6 puntos del PIB en un período de cuatro a cinco años.

Esos niveles no podrán alcanzarse con el mero crecimiento, ya que implican un desplazamiento de la función de ahorro tal, que a cada nivel de ingreso se agreguen tres puntos del PIB de ahorro adicional. Ello sugiere una modificación apreciable en los patrones de comportamiento del consumo y del ahorro privado, así como en el comportamiento del ahorro público. Tampoco parece posible acceder a tales niveles de ahorto apoyándose sólo en modificaciones de los precios relativos. Siendo relevantes, parece necesario acompañarlas con modificaciones institucionales en toda la cadena de formación de capital, de manera de estimular todas las formas de ahorro y asegurar su traspaso eficiente hacia la inversión productiva.

En tal sentido, se requieren mecanismos institucionales que mejoren la eficiencia de los sistemas financieros en la captación, intermediación y asignación de recursos, así como en la supervisión y regulación de los mismos.

El nivel de ahorro en la región no sb́lo es notablemente bajo, si se le compara con el de las economías asiáticas, sino que además su intermediación se canaliza ineficientemente hacia la inversión productiva.

En una concepción integrada del proceso de formación de capital, son relevantes la estabilidad macroeconómica y un clima de crecimiento, así como la pertinencia y estabilidad de los incentivos, la eficacia del marco regulatorio y la calidad de la intermediación financiera, dado que lo que preocupa es tanto generar los recursos de ahorro como facilitar que éstos se canalicen con eficiencia hacia la inversión productiva. 
Lo anterior sugiere que la política financiera debiera ir involucrando a todos los componentes de la cadena de formación de capital. Esta política debería crear y promover explícitamente nuevas fuentes de ahorro, e impulsar un vigoroso desarrollo de las instituciones e instrumentos financieros, teniendo en cuenta las externalidades, los problemas de información y las imperfecciones e incluso vacíos que caracterizan los actuales niveles de desarrollo de los mercados de crédjto y capital en la región; y asimismo atender a los requisitos que demanda el financiamiento de formas específicas de inversión (capital fijo de las empresas, infraestructura, vivienda y otras), así como su necesario complemento en inversión en capital humano.

La relación entre mercado financiero y formación de capital requiere modificaciones institucionales que permitan la inclusión, por un lado, de un segmento de operaciones de largo plazo (lo que daría espacio a inversiones en tecnología, por ejemplo), y por otro, de uno orientado a pequeñas y medianas empresas. Ambos segmentos pueden beneficiarse con innovaciones financieras, que les permitan acceder a esquemas de leasing, fondos de garantía, garantía colectiva de proyectos y concesión de créditos ligados a asistencia técnica.

En la promoción del ahorro privado desempeñan un papel especial las reformas a los sistemas de pensiones. ${ }^{27}$ De igual forma, hay experiencias promisorias en modalidades de ahorro institucional de los trabajadores para optar a subsidios habitacionales. Parecido esquema podría utilizarse para favorecer el crédito a personas o a colectivos asociados en educación y capacitación, aprovechando los sistemas de recaudacion social para realizar el descuento y reembolso automático de tales créditos. Ello pođrá complementarse con mercados secundarios de estos instrumentos, propiciando su diversificación y securitización, de modo de hacerlos atractivos al sistema financiero.

El ahorro público admite diversas combinaciones de aumento de ingresos tributarios, reducciones del gasto público corriente, y saneamiento de las finanzas de las empresas públicas y de los sistemas de previsión. Dos casos estables de ajuste externo, los de Chile y Colombia, también destacan por el logro de un equilibrio fiscal duradero. En ambos casos, el estado de las cuentas públicas antes de la crisis era más alenta-

\footnotetext{
${ }^{27}$ Conviene examinar con atención las implicaciones económicas y financieras de tales reformas, en particular sobre el aborro público y privado, la situación presupuestaria fiscal, la profundización financiera, la administración de riesgos en los mercados de valores y seguros, y la inversión real.
}

dor que en los demás países; a lo largo del proceso de ajuste fiscal ambos países siguieron realizando inversiones públicas esenciales y ambos presentan los mayores coeficientes de ingresos tributarios y corrientes respecto del PIB, netos de privatizaciones. Tales ajustes fiscales se basaron en el crecimiento de la economía, abordando tanto la reducción y racionalización de gastos como una mayor captación de ingresos tributarios y corrientes.

En materia de inversión, hay resultados interesantes en la aplicación de incentivos tributarios que fomentan la retención y reinversión de utilidades, buscando trasladar la carga tributaria desde las empresas a las personas. Un mecanismo poco utilizado es el de financiar la capacitación de personal con una reducción impositiva equivalente, de manera de fomentar la inversión en capital humano.

Otro ámbito relevante para la competitividad es la inversión en infraestructura, habida cuenta del rezago en ella inducido por las restricciones fiscales de los años ochenta. En ese sentido, los procesos de privatización en telecomunicaciones y energía muestran resultados relevantes, con niveles de inversión que han mejorado la cobertura y eficiencia de tales servicios, de un modo que no hubiese sido posible conseguir con fondos públicos. Algo similar está aconteciendo con las inversiones privadas en puertos, aeropuertos y ferrocarriles, si bien cabe reforzar esas tendencias con esquemas de regulación que estimulen la competencia, reduciendo la posibilidad de integración vertical o de subsidios cruzados. El proceso reciente de articulación público-privada en obras viales y en el sector sanitario en Chile y las privatizaciones recientes emprendidas en Bolivia y Perú apuntan en esa dirección.

\section{Complementariedad entre ahorro externo e interno}

El déficit en cuenta corriente ha demostrado ser un importante indicador de la sustentabilidad del equilibrio macroeconómico en economfas abiertas. No se considera inquietante cuando es moderado ( 2 a $3 \%$ del PIB $)^{28}$ o sustentable, en la medida en que se financia principalmente con ingresos de capital de largo plazo. Tampoco cuando no sustituye al ahorro nacional, sino que lo complementa y se refleja más en un incremen-

\footnotetext{
${ }^{28}$ Las autoridades chilenas han ubicado el ahorro externo de tendencia entre 3 y $4 \%$ del pIB (Zahler, 1995), en tanto Summers considera peligroso cualquier déficit en cuenta corriente de balanza de pagos que exceda el $5 \%$ de igual variable (Summers, 1996).
} 
to de la inversión que del consumo, y cuando está bien invertido en actividades transables que mejoran la capacidad de pagos externos.

Las medidas destinadas a estabilizar la afluencia de capital externo han mostrado ser útiles para evitar marcadas distorsiones en precios claves de la economía, como el tipo de cambio y la tasa de interés. Varios gobiernos han intervenido en el mercado cambiario con el objeto de evitar ese efecto; en tales casos, no se han limitado a comprar divisas, sino que además han neutralizado el efecto monetario de esas compras con la emisión de instrumentos de la deuda interna. Chile y Colombia han estimulado el ingreso de recursos a largo plazo y, simultáneamente, han tratado de limitar la entrada de capital a corto plazo mediante la adopción de disposiciones específicas que la desincentivan. En 1995, Brasil y Perú también iniciaron un proceso de aplicación de políticas de este típo, aunque de menor intensidad. Estas políticas no están exentas de costos, ${ }^{29}$ pero han resultado eficaces en etapas de transición a una mayor integración financiera.

En los casos más destacados de manejo de un abundante financiamiento externo tanto dentro como fuera de la región, el problema se ha abordado mediante una serie de medidas integradas de política económica que persiguen una mayor austeridad fiscal y el incremento del ahorro interno, e incluyen la eliminación del seguro cambiario, intervención esterilizadora, la eliminación gradual de los controles aplicados al capital y la salida de recursos, una apreciación moderada de la moneda nacional y la disuasión del ingreso excesivo de capitales de corto plazo (CEPAL, 1995b).

Lo ocurrido en la región en los últimos años indica que la combinación de baja o nula incertidumbre cambiaria, ${ }^{30}$ intervención esterilizadora que frena la

\footnotetext{
${ }^{29}$ Entre ellos destacan los microeconómicos, tal como la menor eficacia de la intermediación financiera. y los macroeconómicos, derivados de las pérdidas cuasi fiscales en que incurre la autoridad monetaria al pagar más por la denda interna que el rendimiento de las reservas internacionales acumuladas en virtud de esta política. No es eficiente intentar neutralizar todas las repercusiones con el tipo de cambio, aun si se las considera transitorias, porque esto puede estimular el arbitraje y reducir el margen de maniobra de la política monetaria.

${ }^{30}$ En abril de 1994, las autoridades financieras mexicanas indujeron la sustitución de valores gubernamentales denominados en moneda nacional (CEJEs y otros) por Tesobonos; el valor de estos instrumentos se indizo sobre la base del típo de cambio, lo que se tradujo en la práctica en una absoluta certidumbre cambiaria. Debido a la sensibilidad del ambiente econornico, y a las turbulencias políticas y económicas, el saldo de los Tesobonos aumento de poco menos de 2000 millones de d́lares en abril a cerca de 29000 millones de dolares en diciembre de 1994.
}

convergencia de las tasas de interés y liberalización del ingreso de capitales favorece la entrada de capital de corto plazo y amplía sus efectos desestabilizadores (FMI, 1995).

El ritmo de apertura de la cuenta de capitales debe adecuarse a la capacidad de absorción y asignación eficaz de recursos externos de la economía, para asegurar la estabilidad macroeconómica y evitar las fluctuaciones del tipo de cambio real. Una devaluación real es esencial para que la liberalización de la cuenta comercial dé resultados satisfactorios y para impedir que la transición productiva y ocupacional tenga un alto costo. ${ }^{31}$ Como los mercados financieros se adaptan más rápido que los mercados reales, abrir prematuramente la cuenta de capital puede conducir a pronunciadas apreciaciones y generar señales contradictorias respecto de la apertura comercial.

Si la apertura financiera es muy brusca y se produce un ingreso masivo de capitales, el déficit en la cuenta corriente puede asumir proporciones que afecten severamente el equilibrio macroeconómico, además de ser insostenible en el mediano plazo. A esto se suma una presión al alza del precio de los activos internos - tierra, propiedades y acciones-, cuyo "efecto riqueza" estimula el consumo e incrementa el déficit. Ello acentúa el riesgo-país y las expectativas de devaluación, ante lo cual la corriente de capital tiende a invertirse, lo que provoca una recesión o exige devaluaciones traumáticas para ajustar el desequilibrio externo.

Sin perjuicio de ello, conviene prestar atención a las características propias de cada país. De hecho, la memoria histórica en la política económica o la capacidad institucional de un país puede desaconsejar el uso de determinados instrumentos, entre otros, el control de capitales. En otros casos, puede ser necesario iniciar simultáneamente un conjunto de reformas económicas por consideraciones de economía política, como ha ocurrido en Bolivia y Perú, o bien un historial de hiperinflación puede exigir la adopción de anclas cambiarias y sistemas de libre convertibilidad que permitan captar el ahorro externo a fin de que contribuya a la estabilización y el crecimiento, como ha ocurrido en Argentina.

\footnotetext{
31 Entre 1987 y 1991 , seis países de la región iniciaron una apertura comercial o tomaron medidas con el objeto de profundizarla, proceso que coincidió con una etapa de marcada apreciación de sus monedas. Por lo tanto, la combinación de mayor entrada de capital y menor costo de las importaciones provocó un aumento desmesutado de estas úlkimas. Vease cepas, 1992a.
} 
De todos modos, continúan siendo válidas las razones que aconsejan no sobrepasar un prudente desequilibrio en la cuenta corriente. En estos casos de abundante apoyo en el ahorro externo, se imponen aún mayores exigencias en materia de austeridad fiscal y evolución de la productividad, de modo de contrarrestar excesos de gasto y las tendencias a la apreciación de la moneda nacional.

\section{Competitividad y desarrollo productivo}

En tanto que el comercio mundial muestra mayor $\mathrm{di}$ namismo en los productos con mayor contenido tecnológico, en particular las manufacturas no basadas en recursos naturales, el desafío competitivo insta a redoblar los esfuerzos por diversificar la oferta exportadora, incorporar en ella más tecnología y productividad e incrementar la calidad y la profundidad de los enlaces entre las exportaciones y el resto de los sectores productivos. ${ }^{32}$

Desde esa óptica, la CEPAL recoge ciertas interrogantes presentes en el debate regional:

¿La especialización actual es un tránsito a una industrialización que hace uso más intensivo de tecnología y capital humano, o es una estación terminal, con repercusiones limitadas a los sectores primarios? ¿Qué efecto tendrá esta especialización en crecimiento, empleo y distribución del ingreso? ¿Permite ella insertarse adecuadamente en las corrientes dinámicas del comercio internacional? y si no es así, ¿qué alternativas hay?, ¿qué políticas?

\section{a) Diseño de politicas}

Al respecto, coexisten en la región varios enfoques, que van desde la eliminación de las políticas industriales -excepto las que apoyan la competitividad sistémica- hasta los que favorecen políticas sectoriales que complementen las políticas horizontales, es decir, aquéllas orientadas a fomentar los mercados de capitales.

Se percibe también una clara asimetría en la evolución de los instrumentos disponibles para el fomento productivo, pues mientras disminuyen los tradicionales, no se desarrollan otros más adecuados a la rea-

\footnotetext{
${ }^{32}$ Para crecer al $6 \%$ anual se necesitan incrementos en el volumen exportado no inferiores al 10 a $12 \%$ anual. Esto parece difícil de conseguir con la actual canasta exportadora, ya que en 1985-1994, período de repunte en el comercio internacional, el comercio mundial de productos básicos no superó incrementos de $4 \%$ anual (algo menos de la mitad del rítmo de expansión del comercio total y cerca de un tercio del incremento del comercio de manufacturas).
}

lidad de economías abiertas y a la evolución de los acuerdos multilaterales.

Hoy en la región se privilegian las políticas horizontales, buscando perfeccionar mercados de factores, con neutralidad respecto al tipo de actividades o empresas involucradas. Hay debilidades sí en el manejo de situaciones sectoriales y de reconversión productiva, así como en el respaldo a sectores innovadores y en el grado de coordinación y colaboración públicoprivada (Rosales, 1994).

La búsqueda apunta a un equilibrio entre la disciplina macroeconómica y las políticas de desarrollo productivo, con una clara comprensión de los peligros de la intervención pública y los excesos del proteccionismo. Hay una percepción menos difundida de las fallas o insuficiencias de mercado en la promoción de la competitividad y el progreso técnico, así como una cierta subestimación de la factibilidad de procesos de aprendizaje de fomento productivo en el sector público.

Los requisitos técnicos de los instrumentos tienden a apoyarse en instituciones de mercado, con incentivos acotados, decrecientes y autodesmontables, al lograrse resultados, así como con desempeños evaluables y objetivos limitados y que concuerden con la capacidad técnica e institucional del sector público (Rosales, 1994).

En tal sentido, las políticas de desarrollo productivo no buscan "elegir ganadores" sino más bien generar las condiciones para que ellos surjan. Apuntan a incrementar la productividad total de los factores, a promover la generación y difusión de tecnología, a favorecer la inversión en recursos humanos y a fomentar eslabonamientos y cadenas productivas en torno a recursos naturales, incluyendo el turismo.

Incorporar el mejoramiento de la infraestructura y la promoción de la competencia como factores de la competitividad es uno de los aprendizajes de las reformas económicas en los años noventa. Las políticas de ajuste y saneamiento fiscal han limitado la capacidad del sector público para invertir en infraestructura, abriendo una oportunidad para explorar la participación privada en su financiamiento.

El fomento de la competencia pasa a ser un componente esencial del desarrollo productivo, dado que la eficacia de los mercados radica en su carácter competitivo, su transparencia y su fácil acceso. Es preciso, entonces, desregular los mercados competitivos, regular los mercados de monopolios naturales y "completar" mercados truncos o débiles, como los de tecnología, capacitación, capital de largo plazo y crédito 
a la pequeña y mediana empresa (PYME) o para la inversión en recursos humanos.

La política más adecuada para estimular la eficiencia es la competencia. Cuando ésta no es posible, la regulación opera como la segunda mejor opción. De allí la importancia de fortalecer la tecnificación, la autonomía y la capacidad institucional de los organismos de regulación, como instrumento de fomento de la competitividad.

Los procesos de privatización han generado diversos logros en materia de eficiencia y mayor inversión, logros que han sido mayores cuando se ha promovido la competencia con esquemas de regulación de monopolios naturales que abarcan aspectos tarifarios, de inversion, de cobertura y normas sobre competencia y protección al consumidor.

\section{b) Sistemas de innovación y difusión tecnologica ${ }^{33}$}

Lo que la región asigna al fomento y a la difusión tecnológica, en términos de montos, incentivos y capacidad institucional, es insuficiente. No da cuenta de la importancia estratégica del progreso técnico para economías abiertas y competitivas y el tema no aparece como prioritario en las agendas nacionales. En consecuencia, el rezago competitivo se puede ir acentuando.

El incremento de la productividad está estrechamente ligado a los avances en innovación, fomento tecnológico y promoción de la calidad. Para ello es imprescindible que la política pública apoye el desarrollo del mercado tecnológico, fortaleciendo la infraestructura científico-tecnológica y los vínculos entre ésta y el aparato productivo. Esa idea se recoge en el concepto de "sistema innovativo", que incluye: centros sectoriales de investigación y difusión tecnológica, de fomento de la calidad, la diferenciación de marca y el diseño, y de técnicas de gestión y de formación de recursos humanos, entre otros.

El mayor gasto en tecnología en la región corresponde al realizado a través de los institutos tecnologicos del sector público, el que en la mayoría de los casos no está sujeto a periódicas evaluaciones de rendimiento o pertinencia. De allí que se proponga una transición gradual hacia una asignación de recursos que los vincule a resultados mediante indicadores de desempeño,

${ }^{33}$ En estudios anteriores de la CEPAl se han examinado aspectos como la difusión de tecnología (CEPAL, 1995c, cap.VIII), el fortalecimiento de la infraestructura tecnológica (CEPAL, 1992b, cap.V) y el financiamiento de las actividades de investigación y desarrollo (CEPAL, 1990, cap. V). introduciendo mayor competencia en el sector sobre la base de proyectos concursables.

Es probable que esto conduzca a un aumento de la participación privada en la gestión y financiamiento de esos institutos, lo que podría dotarlos de mayor autonomía y flexibilidad en el manejo de fondos, junto con robustecer su contacto con la base productiva. Tal transición, en todo caso, ha de ser gradual, preservando la investigación básica y las áreas con marcadas externalidades en el ámbito público.

\section{c) Capacitación}

Es indispensable propiciar un aumento significativo de los gastos de las empresas en capacitación, mediante la reorientación de los incentivos tributarios y financieros. ${ }^{34}$ Los contenidos actuales en capacitación, en general, son inadecuados y obsoletos; están bastante desvinculados de las necesidades de las empresas y el sistema de capacitación tiene vínculos débiles con la educación técnica y secundaria. ${ }^{35}$

Por ello, sería útil modificar ciertos aspectos de] funcionamiento de las instituciones públicas de capacitación, favoreciendo una mayor participación de las empresas y agrupaciones empresariales en la definición de sus orientaciones, la adopción de más criterios de mercado en su gestión y la vinculación de los programas de capacitación con las prioridades y programas tecnologicos.

El perfeccionamiento del mercado de capacitación exige una mayor articulación entre oferta y demanda; la adopción de normas sobre contenido, calidad y pertinencia, y la provisión de mejores incentivos que recojan la externalidad de estas inversiones. Esta tarea se realizará probablemente con menor costo y mejores resultados si se actúa en instancias tripartitas con organizaciones de empresarios y trabajadores.

\section{d) Institucionalidad y desarrollo productivo}

Readecuarse al desafío de internacionalización plantea retos a la institucionalidad pública y privada, ya que requiere un sector público más comprometido

\footnotetext{
${ }^{34}$ El trabajador medio de la región recibe sólo dos a cuatro semanas de capacitación en sus $\mathbf{4 5}$ años de vida laboral, lo que se compara con 20 a 25 semanas que recibiría si se asignara el $1 \%$ de la planilla de sueldos y salarios a este rubro, de acuerdo con las normas internacionalmente aceptadas.

$\left.{ }^{35} \mathrm{~A}\right]$ respecto, se ha sugerido la conformación de sistemas modulares flexibles, con homologacion de los programas de estudio entre educación secundaria y técnica post-secundaria, permitiendo validar cursos aprobados en unas y otras, mediante un sistema de certificación de calificaciones con participación directa de las empresas privadas y publicas. Esto permitiría evaluar y ajustar la pertinencia laboral de los conocimientos adquiridos (Rosales, 1994).
} 
con el fomento productivo y el esfuerzo exportador y una mayor cooperación público-privada.

Tal cooperación ayudaría a mejorar la evaluación y aplicación de incentivos, a respaldar el acceso a mercados e inversiones en el exterior, y a atender los problemas sectoriales y de reconversión productiva. Otros aspectos que precisan mayor colaboración público-privada se vinculan con la calidad y la diferenciación de marca, con una mayor presencia privada nacional en las redes de comercialización y en operaciones conjuntas con empresas locales en los mercados de destino, así como con la necesidad de ampliar el espacio a la inversión privada en infraestructura.

En este mismo plano institucional, se propone considerar la creación de centros de fomento de la productividad, encargados del monitoreo de la capacidad competitiva y de las tendencias tecnologicas y comerciales de un determinado sector. Se trataría de centros tripartitos, integrados por el gobierno, universidades y centros tecnologicos, por una parte, y por organizaciones empresariales y de trabajadores, como representantes del sector privado.

La cooperación entre empresas y asociaciones privadas es básica para mejorar las tareas de promoción y comercialización, abordar el control de calidad y generar estrategias privadas de internacionalización. También para promover relaciones laborales equilibradas que estimulen la capacitación y la productividad, la flexibilidad concertada y la motivación laboral, base de un recurso humano de calidad, hoy el principal factor competitivo.

Se observa aquí una debilidad relativa de las or- ganizaciones empresariales y sindicales, así como del propio sector público. Pero también experiencias germinales y valiosas que han permitido potenciar la colaboración y coordinación entre el sector público y el privado en el desarrollo productivo, velando por una adecuada distribución de responsabilidades en los ámbitos en que cada uno cuenta con ventajas relativas. ${ }^{36}$

Hay logros y debilidades en los esquemas de concertación para el fomento productivo. En todo caso, el balance permite apreciar una reducción de los costos de coordinación entre los agentes productivos, y entre éstos y los gestores de políticas públicas, habiéndose mejorado el acceso a la información y facilitado la actualización de los incentivos.

Promover innovaciones institucionales y en el comportamiento de los actores sociales, compatibles con escenarios de economías abiertas, orientadas a la construcción de competitividad auténtica, es otra dimensión clave de la reforma económica. Hay un espacio relevante para que las políticas públicas apoyen el fortalecimiento de actores colectivos responsables e informados que otorguen viabilidad a la concertación estratégica entre ellos.

Las políticas de desarrollo productivo cuentan con un potencial para incidir tanto en el crecimiento como en la equidad. Concretarlo, sin embargo, exige más esfuerzos para perfeccionar el diseño y la gestión de las políticas de fomento productivo, realizando evaluaciones de ellas, de modo de favorecer los procesos de aprendizaje en el sector público y mejorar la eficacia de los instrumentos de fomento productivo.

\section{Bibliografía}

CEPAL (Comisión Económica para América Latina y el Caribe) (1990): Transformación productiva con equidad. LC/G.1601P, Santiago de Chile. Publicación de las Naciones Unidas, $\mathrm{N}^{\circ}$ de venta S.90.HI.G.6.

(1992a): La política cambiaria en América Latina y el Caribe al inicio de los noventa, Estudio Económico de Amé rica Latina y el Caribe 1991, vol. I, LC/G. 1741-P, Santiago de Chile.

(1992b): Equidad y transformación productiva: un enfoque insegrado. LC/L.668, Santiago de Chile, 6 de enero. (1993): Las finanzas públicas de América Latina en la década de 1980. Cuadernos de la CEPAL, $\mathrm{N}^{\circ} 69$, Santiago de Chile. Publicación de las Naciones Unidas, $\mathrm{N}^{0}$ de venta E.92.II.G.10.

(1994): El gasto social en América Latina: un examen cuantitativo y cualitativo, Cuadernos de la CEPAL, $\mathrm{N}^{\circ} 73$, LC/G.1854-P, Santiago, Chile.

(1995a) Balance preliminar de la economía de América Latina y el Caribe 1995, LC/G.1892-P, Santiago de Chile. (1995b): Movimientos de capitales: desafios y opciones de políica, trabajo presentado en la Reunión de Coordinadores Nacionales del Grupo de Río, LC/R. 1559, Santiago de Chile.

(1995c): Políticas para mejorar la inserción en la eco. nomia mundial, LC/G. 1800/Rev.1-P, Santiago de Chile.

(1995d): Panorama social de América Latina 1995. LC/G. 1886-P, Santiago de Chile.

(1996a): Fortalecer el desarrollo. Interacciones entre macro y microeconomía, LC/G.1898 (SES.26/3), Santiago de Chile.

\footnotetext{
${ }^{36}$ Entre ellas, la Cámara Ejecutiva Estructural (Brasil), ej Consejo Nacional de Competitividad (Colombia), el Foro de Desarrollo Productivo (Chile y de pronta gestación en Bolivia y Paraguay), así como las experiencias andinas de "cadenas de valor".
} 
(1996b): América Latina y el Caribe: quince años de desempeño económico, Santiago de Chile. Publicación de las Naciones Unidas, $\mathrm{N}^{\circ}$ de venta S.96.II.G.3.

FMI (Fondo Monetario Intemacional) (1995): International Capisal Markets. Developments, Prospects and Policy Isstues, Word Econonic and Financial Surveys, Washington D.C., agosto.

Held, G. y A. Uthoff (1995): Indicators and Determinants of Savings for Latin America and the Caribbean, CEPAL, Working Paper $\mathrm{N}^{\circ} 25$, Santiago de Chile. CEPAL.

Hofman, A.A. (1995): Economic growth and fluctuation in Latin America. The long run, trabajo presentado a la conferencia Development Strategy after Neoliberal Economic Restructuring in Latin America, Miami, Florida, Centro Norte-Sur/ Universidad de Miani, mimeo.

(por publicarse): Capital stock in Latin America: a 1994 update, Cambridge Joumal of Economics. Nueva York, Academic Press Ltd.

Marcel, M. (1989): Privatización y finanzas públicas: el caso de
Chile, Colección Estudios CIEPLAN, $\mathrm{N}^{\circ} 26$, Santiago de Chile, Corporación de Investigaciones Economicas para América Latina (CIEPLAN).

Massad, C. y N. Eyzaguirre (1990): Ahorro y formación de capial: experiencias latinoamericanas, Colección estudios políticos y sociales, Santiago de Chile, CEPAL/Programa de las Naciones Unidas para el Desarrollo (PNUD)/Ed, Latinoarnericana.

Mortimore, M. (1995): América Latina frente a la globalización, Desarrollo Productivo, $\mathrm{N}^{\circ} 23$, Santiago de Chile, CEPAL, División de Desarrollo Productivo y Empresarial.

Rosales, O. (1994): Política industrial y fomento de la competitividad, Revista de la CEPAL, $N^{\circ}$ 53, LC/G.1832-P, Santiago de Chile.

Summers, L. (1996): Tent lessons to learn, The Economist, Londres, 5 de enera.

Zahler, R. (1995): Discurso en Encuentro Financiero JCARE, julio, Instituto Chileno de Administración Racional de Empresas (ICARE). 